bioRxiv preprint doi: https://doi.org/10.1101/329664; this version posted May 24, 2018. The copyright holder for this preprint (which was not certified by peer review) is the author/funder. All rights reserved. No reuse allowed without permission.

\title{
MTAP loss correlates with an immunosuppressive profile in GBM and its substrate MTA stimulates alternative macrophage polarization
}

Landon J. Hansen ${ }^{1,2,3}$, Rui Yang ${ }^{1,2}$, Karolina Woroniecka ${ }^{1,2}$, Lee Chen ${ }^{1,2}$, Hai Yan ${ }^{1,2}$, Yiping He 1,2,*

From the ${ }^{1}$ The Preston Robert Tisch Brain Tumor Center, Duke University Medical Center, Durham, NC, USA;

${ }^{2}$ Department of Pathology, Duke University Medical Center, Durham, NC, USA; ${ }^{3}$ Department of Pharmacology and Cancer Biology, Duke University Medical Center, Durham, NC, USA; ${ }^{4}$ Department of Neurosurgery, Duke University Medical Center, Durham, NC, USA

\section{*Corresponding Author:}

Yiping He, PhD, 203 Research Drive, Medical Science Research Building 1, Room 199A

Durham, NC, USA 27710

Phone: (919) 684-4760

E-mail: yiping.he@duke.edu

Keywords: MTAP, GBM, macrophages, M2, MTA, adenosine

\begin{abstract}
Glioblastoma (GBM) is a lethal brain cancer known for its potent immunosuppressive effects. Loss of Methylthioadenosine Phosphorylase (MTAP) expression, via gene deletion or epigenetic silencing, is one of the most common alterations in GBM. Here, we show that MTAP loss in GBM cells is correlated with differential expression of immune regulatory genes. In silico analysis of gene expression profiles in GBM samples revealed that low MTAP expression is correlated with reduced proportions of $\gamma \delta \mathrm{T}$ cells, fewer activated CD4 cells, and an increased proportion of M2 macrophages. Using in vitro macrophage models, we found that methylthioadenosine (MTA), the metabolite that accumulates as a result of MTAP loss in GBM cells, promotes the immunosuppressive alternative activation (M2) of macrophages. We show that this effect of MTA on macrophages is independent of IL4/IL3 signaling, is mediated by the adenosine $A_{2 B}$ receptor, and can be pharmacologically reversed. This study suggests that MTAP loss in GBM cells contributes to the immunosuppressive microenvironment, and that MTAP status should be a factor for consideration in understanding GBM immune states and devising immunotherapy-based approaches for treating MTAPnull GBM.
\end{abstract}

\section{INTRODUCTION}

Immunotherapy possesses enormous potential for treating cancer and has reshaped the way we understand and treat certain cancer types $(1,2)$. Despite recent progress, however, the promise of immunotherapy-based approaches for treating brain tumors, in particular high grade glioblastoma (GBM), remains to be fully realized (3-5). GBM is the most common and lethal brain tumor, with a dismal median survival of 12-15 months from the time of diagnosis (6). It is also a cancer characterized by its immune-suppressive nature. It has been wellestablished that GBM cells actively employ multiple strategies to escape immune surveillance and to create an immunosuppressive microenvironment (7-9). As such, to fully harness the power of immunotherapy for GBM requires better understanding and more effective strategies for countering the tumors' immunosuppressive effects.

Recent genomic studies have provided insights into the molecular mechanisms of GBM pathogenesis, revealing the most commonly mutated genes in tumor cells $(10,11)$. Gliomas can be classified based on their genetic alterations and gene expression profiles into subtypes that predict tumor characteristics and patient prognosis (12). Further studies, in both glioma and other types of cancer, have associated genetic alterations with tumor cells' evasion of immune surveillance and manipulation of the immune microenvironment, 
providing new rationale for tailoring treatment based on cancer cells' genetic composition (13-15). As an example, recent discoveries have linked IDH1 mutations in glioma to immune evasion through interference with immune activation pathways, providing new opportunities for devising highly specific immunological treatments (1619). Thus, identifying additional cancer-specific mutations that confer a similar immune escape/ suppression-based advantage to glioma cells will likely lead to new rationale for immunotherapeutic designs.

One of the most common genetic alterations in GBM, occurring in approximately $50 \%$ of all cases, is the homozygous deletion or epigenetic silencing of methylthioadenosine phosphorylase $(M T A P)(10,20)$. We have recently demonstrated that MTAP deletion is associated with increased tumorigenesis and with shortened disease-free survival in GBM patients (Hansen, et al, submitted). MTAP is a metabolic enzyme that functions in the salvage pathway of adenine and methionine, and loss of MTAP results in the accumulation of its direct metabolite substrate, methylthioadenosine (MTA), in both intracellular and environmental compartments (21-23). MTA is known to be functionally active within cells as an inhibitor of methyltransferases $(22,23)$. This metabolite has also been shown to suppress cell proliferation via different, cellular context-dependent mechanisms, including targeting the Akt signal pathway and interfering with intracellular protein methylation in $\mathrm{T}$ cells (24), or acting through adenosine receptors on the cell surface of melanoma cell lines (25). Studies on mechanism of pathogen-induced host inflammatory responses have linked MTA to downregulation of TNF $\alpha$ production by macrophages through engaging adenosine receptors (26), and have revealed a role of MTA in controlling host inflammation response, such that MTA has been used as an immunosuppressive drug for treating colitis, liver inflammation, brain inflammation and autoimmunity in animal models (27-29). Lastly, MTA has been shown to be elevated in the blood of septic patients (30) and in the urine of children with severe combined immunodeficiency (SCID) (31), further supporting its role in regulating the immune response.

In this study, we investigated the link between

MTAP loss in GBM cells and the GBM microenvironment. We show that MTAP expression correlates with the expression of genes regulating innate or adaptive immune response in both experimental cell models and in GBM samples. We reveal that in GBM tissues, low expression level of MTAP is associated with altered immune cell populations indicative of a more immunosuppressive context. In particular, we provide evidence that MTAP loss-induced MTA accumulation stimulates M2 alternative macrophage activation. We illustrate that this effect of MTA on macrophages is independent of IL4/IL3 signaling, is mediated by the adenosine $\mathrm{A}_{2 \mathrm{~B}}$ receptor and STAT3 signaling, and is distinct from the actions of adenosine. Finally, we show that the MTA-induced alternative macrophage activation can be pharmacologically reversed. These results provide a basis for blocking adenosine $A_{2 B}$ receptor signaling as a strategy to potentiate immunotherapy targeting MTAPnull GBMs.

\section{RESULTS}

MTAP loss in GBM cells is associated with an immunosuppressive gene expression profile

We established patient-derived GBM cell lines, verified MTAP status, and used the affymetrix gene expression microarray to characterize their global gene expression profile (L. Hansen, et al., submitted). Analysis of differentially regulated genes (unpaired ANOVA comparing MTAP WT vs MTAP null cell lines) revealed a list of downregulated inflammatory pathways, including the KEGG pathway of antigen processing and presentation (Fig. 1A). One group of genes common to all these pathways are the human leukocyte antigen (HLA) genes, which were found to be consistently downregulated in tumor cells that lack MTAP (Fig 1B). We compiled a gene set with all HLA genes included in the gene expression microarray (Supporting data Table 2) and performed gene set enrichment analysis (GSEA) as previously described (32) to examine the correlation of this set of genes with MTAP status. GSEA confirmed that MTAP null cells displayed markedly lower expression of HLA genes, including HLA Class I and both $\alpha$ and $\beta$ chains of HLA class II (Fig. 1C). Consistent with our finding of differentially expressed inflammatory pathways, GSEA using gene sets of inflammatory cytokines showed that MTAP null cells had reduced expression of inflammatory cytokines compared to MTAP WT cells (Fig. 1D). Examination of individual genes showed that while several regulators of the adaptive immune response were affected (IL2, CTLA4, and CD44), most differentially expressed genes were associated with the innate immune response, including those that regulate monocyte/macrophage proliferation, differentiation and activation, such as CSF1, IL13, IL34, IL37, ALOX5, and toll-like receptor related genes, TLR4, TIRAP, and LY96 (Fig. 1E). Collectively, these results illustrate that MTAP expression correlates with numerous immune-regulatory genes in a manner suggesting that loss or reduction of MTAP expression contributes to the immune-suppressive nature of GBM cells.

\section{Loss of MTAP expression is associated with an immunosuppressive molecular profile in GBM}

To evaluate the relevance of the above in vitro findings to GBM, we took advantage of The Cancer Genome Atlas (TCGA) large gene expression dataset $(33,34)$ to test the link between MTAP expression and the immune status of GBM tumor samples. First, we analyzed expression of individual inflammatory mediators/ 
regulators from the TCGA GBM dataset. Consistent with the findings from the in vitro models, this analysis showed that low MTAP expression was correlated with lower expression of cytokines known to promote inflammatory responses (e.g. CCL4, CCL5, IL2, TNF, IFNG), and with higher expression of genes known to be involved in regulating monocyte/macrophage activation, including TGFB1, CHI3L1, CHII3L2, HRH1, TREM2, and P2RY13 (Supporting Fig. S1).

To test the association of MTAP expression with the immune cell profile in GBM we employed CIBERSORT, a recently developed method for deconvoluting gene expression data and estimating immune cell fractions in human cancers (35-37). This method was chosen for several reasons: (i) it has been successfully used for analyzing a large number of samples across multiple cancer types (36), (ii) it is readily compatible with the microarray-based platform of the largest available GBM expression dataset, and (iii) this approach's unique consideration of data normalization and noise control can be particularly helpful when analyzing GBM samples which are known for their heterogeneity and diffusiveness (38). To validate the application of this approach to glioma samples, we first evaluated the TCGA low-grade glioma dataset (39) by testing the immune cell components in tumors with wildtype or mutant $I D H 1 / 2$, since the effect of $I D H$ mutations on glioma immune suppression has been well defined (1719). In particular, it has been shown that $I D H$ mutation is correlated with lower levels of CD8+ and CD4+ T cells and lower macrophage infiltration $(17,18)$. CIBERSORT analysis of the low grade glioma gene expression dataset from TCGA ( $\mathrm{n}=530$ samples) (39) revealed a profile consistent with these previously reported observations (Supporting Fig. S1). Interestingly, CIBERSORT also revealed a previously unknown effect of IDH mutation on numbers of macrophages, mast cells, plasma cells, and B cells, with a higher representation of each cell type, except macrophages, in $I D H$-mutant gliomas (Supporting Fig. S2).

We extended the same analysis to the GBM dataset from TCGA (385 GBM patient samples) (10) to examine the link between MTAP loss and the GBM immune microenvironment. As MTAP alteration can occur through homozygous gene deletion or epigenetic silencing, we compared the two groups of patients with the highest and lowest MTAP expression (upper and lower quartiles, $n=96$ each) (Supporting Fig. S3). This analysis revealed reduced fractions of activated CD4 T cells in tumors with low MTAP expression (Fig. 2A). Additionally, two types of innate immune cells were identified as differentially represented between these two groups of tumors. First, there was a lower fraction of $\gamma \delta \mathrm{T}$ cells in the low-MTAP expressing tumors (Fig. 2B); and second, a significantly higher fraction of M2 macrophages were observed in low-MTAP tumors compared to high MTAP-expressing tumors (Fig. 2C).

To corroborate the findings from CIBERSORT analysis, we utilized a recently developed platform for identifying individual immune cell types based on a dataset of 366 microarrays compiled from multiple independent studies (40). This data set was previously used to generate a list of 782 genes that are specific to immune cell subpopulations (i.e. not expressed in tumor cells or normal tissue) (40). We analyzed this list of genes in the TCGA GBM dataset and found that among the 641 of these genes for which expression data was available, 306 of them were differentially expressed between the MTAP-low and MTAP-high GBM populations (upper quartile vs lower quartile, $\mathrm{n}=96$ each group, t test $P$ value $<0.05$ ), with an even distribution between the two groups (146 genes upregulated in MTAP-low tumors, 159 genes upregulated in MTAP-high tumors) (Fig. 2D). When these two derivative groups of genes were linked to their respective immune cell subtypes using the previously defined immune cell gene signatures (40), we found that the genes upregulated in MTAP-low tumors were predominantly associated with macrophages and monocytes, while those genes upregulated in MTAP-high tumors were expressed in activated CD4 T cells, natural killer cells, and $\gamma \delta$ T cells (Fig. 2E; Supporting Figs. S4 and S5). Collectively, the findings from our various analyses on the gene expression profiles of low MTAP and high MTAP expressing GBM samples suggest a reduction in immune-reactive T cells (41) and an increase in immunosuppressive M2 macrophages (42) in samples with low MTAP expression, supporting the notion that MTAP deficiency is linked to a more immunosuppressive GBM microenvironment.

\section{MTA stimulates alternative activation of macrophages}

Among the aforementioned immune cell types that were found to be differentially represented between $M T A P$-low versus MTAP-high GBMs, the potential impact of MTAP loss on macrophage populations was particularly intriguing. Macrophages are the most abundant immune cell type in GBM, representing as many as half of all cells in the tumor mass (43), where they are known to play an immunosuppressive/protumoral role (42). Macrophages can be regulated by adenosine signaling (44), which potentiates the effect of cytokines in promoting alternative macrophage activation through adenosine $\mathrm{A}_{2}$ receptors (45). Studies focusing on pathogenic mechanism and treatment of pathogen-induced host inflammatory responses have found that MTA can suppress Lipopolysaccharide (LPS)-induced expression of inflammatory response genes, such as TNF, via adenosine $\mathrm{A}_{2}$ receptors $(26,46)$. These indications, together with our finding of a higher fraction of M2 macrophages in low-MTAP-expressing GBMs as 
described above, led us to hypothesize that MTA potentiates M2 macrophage activation through adenosine receptor signaling.

We tested this hypothesis using the wellestablished murine RAW 264.7 macrophage cell line model $(45,47)$. As expected, treatment of RAW 264.7 cells with M2 macrophage-inducing Th2-type cytokines, interleukin (IL)-4 and IL-13, drove the cells toward the alternative type of activation, as demonstrated by the upregulated expression of Arginase 1 (Arg1), a canonical marker for M2 macrophages (48) (Fig. 3A). When MTA was used in combination with IL-4/IL-13, induction of Arg1 expression was dramatically augmented (Fig. 3B). Remarkably, when MTA was used as a single agent to treat the cells, upregulated expression of Arg1 was also observed (Fig. 3C). This effect was not limited to RAW 264.7 cells as it was also observed in the murine BV-2 microglial cell line and in the human THP-1 cell line (Fig. 3D, Supporting Fig. S6A). Notably, the effect of MTA on macrophages was distinct from that of IL-4 or IL-13, as treatment of cells with MTA attenuated the IL-4/IL-13induced expression Pparg and Mrc1, marker genes associated with the M2a macrophage subtype (Fig. 3E; Supporting Fig. S6B) $(49,50)$. Also distinct from the effect of IL-4 or IL-13 was that MTA activated the expression of Vegfa, a classic feature of the M2d subtype of alternatively activated macrophages (Fig. 3F and $\mathbf{G}$ ) (50). In agreement with this finding from the in vitro model, we revisited the GBM gene expression data (TCGA) and validated that in GBM patients VEGFA expression was significantly higher in samples with low MTAP expression (Fig. 3H). Collectively, these results suggest that MTA promotes alternative macrophage activation resembling the M2d subtype and that this process likely occurs in MTAP deficient GBMs.

To validate that the phenotype induced by exogenously administered MTA is relevant to the GBM extracellular microenvironment, we generated an isogenic MTAP-null derivative of the murine GBM cell line CT2A. As expected, CRISPR-mediated homozygous deletion of MTAP in CT-2A cells led to the accumulation of MTA in the culture media (Fig. 3I). We then tested the response of macrophages to spent media from the MTAPnull cell line as a way of simulating the tumor microenvironment. Exposure of RAW 264.7 cells to spent media from MTAP-null CT-2A cells indeed induced Arg1 expression. While exposure to the spent media from parental CT-2A (MTAP wildtype) cells had a minimal effect on Arg1 expression, the addition of exogenous MTA to the conditioned media was able to stimulate an alternative activation response (Fig. 3J). Together, these results support the hypothesis that MTA in the extracellular compartment of MTAP-null GBM cells can work in concert with known M2 macrophage-stimulating cytokines in altering tumor associated macrophages, and/or directly promoting the alternative activation of macrophages as a single agent.

\section{Regulation of macrophage activation by MTA requires the adenosine $A_{2 B}$ receptor and STAT3}

Previous work has shown that the action of adenosine in modulating the innate immune response to cytokine signaling is achieved through the adenosine $\mathrm{A}_{2}$ receptors (50). We tested whether the effects of MTA are also mediated through these receptors using specific antagonists of $\mathrm{A}_{2 \mathrm{~A}}$ and $\mathrm{A}_{2 \mathrm{~B}}$ receptors. We found that an $\mathrm{A}_{2 \mathrm{~A}}$ receptor antagonist, Istradefylline, had only minimal effect on MTA-induced Arg1 expression. In contrast, an antagonist of the $\mathrm{A}_{2 \mathrm{~B}}$ receptor, PSB0778, while failing to block the effect of IL-4/IL13 as expected, potently attenuated the expression of Arg1 induced by MTA (Fig. 4A), an effect which was also seen in the BV-2 cell model (Fig. 4B). Furthermore, PSB0778 also blocked the induction of Arg1 expression by the spent media of MTAP-null GBM cells (Fig. 3J), and attenuated other MTA-stimulated M2 marker genes, including Vegfa, Timp1, and IL10, while countering the inhibitory effect of MTA on Mrc1 expression (Fig. 4C; Supporting Fig. S6B). These results suggest that MTA acts through the adenosine $A_{2 B}$ receptor to regulate macrophage activation.

The essential role of the adenosine $A_{2 B}$ receptor in mediating the effect of MTA led us to ask whether a sustained contribution/function of this signaling pathway is required for maintaining the resultant macrophage activation state. To address this question, we treated the cells with the $A_{2 B}$ receptor antagonist at a delayed time point following treatment with M2-inducing cytokines and/or with MTA. We found that treatment of the already activated macrophages with the adenosine $A_{2 B}$ receptor antagonist was still able to abolish Arg1 expression (Supporting Fig. S6C and D), suggesting the effect of MTA can be pharmacologically reversed.

To further illuminate the downstream mediators of MTA-stimulated $A_{2 B}$ receptor signaling, we tested the role of transcriptional regulators CREB and STAT3, as these are reported to function downstream of adenosine receptors and are known to regulate Arg1, Vegfa, and IL10, among other genes (51-55). We found that the inhibition of STAT3 completely abrogated the MTAinduced expression of all three genes. In contrast, inhibition of CREB had only marginal or no effect on MTA-induced gene expression (Fig. 4D). These results suggest that STAT3 is a necessary component of M2d macrophage polarization induced by MTA-stimulated $\mathrm{A}_{2 \mathrm{~B}}$ receptor signaling.

\section{MTA and adenosine activate distinct yet overlapping signaling pathways}

As both adenosine and MTA signal through adenosine receptors, we sought to determine if there were 
any quantitative or qualitative differences in their effect on macrophage activation. We treated RAW 264.7 macrophages with equimolar concentrations of adenosine or MTA and tested the expression of macrophage activation markers in response to each metabolite. To our surprise, we found that MTA much more potently stimulated expression of Arg1, Vegfa, and Timp1 than did adenosine (Fig 5A). In addition, MTA was unique in its ability to suppress Pparg expression (Fig. 5B). Furthermore, while MTA and adenosine similarly upregulated IL10 expression (Fig. 5C), the impact of adenosine on IL10 (and Timp1) was impervious to PSB0778, suggesting adenosine was acting through a different receptor than MTA to induce expression of these genes (Fig. 5A and 5C). Notably, the impact of MTA on IL10 was also only partially reduced by $\mathrm{A}_{2 \mathrm{~B}}$ receptor antagonism (Fig 4C and 5C).

We then tested the role of downstream mediators in mediating the response of MTA and adenosine signaling. We found the effect of MTA and adenosine on IL10 expression were both effectively blocked by betulinic acid, an inhibitor of transcription factor C/EBP (CEBPA/CEBPB) (Fig. 5D), consistent with reports of C/EBP being a critical regulator of IL10 expression (56) and indicating a partial convergence of the adenosine and MTA signaling pathways through this transcription factor. Furthermore, similar to what we had observed with MTA (Fig. 4D), induction of IL10 expression by adenosine was also blocked by stattic, indicating adenosine-stimulated IL10 requires STAT3 (Fig. 5E). However, whereas MTA-induced expression of IL10 was independent of CREB (Fig. 4D), addition of CREB inhibitor 666-15 effectively blocked IL10 expression in response to adenosine (Fig. 5E), indicating that in the downstream signaling pathways there are distinct mechanisms responsible for MTA and adenosinemediated responses in macrophages.

To further illuminate the distinct/overlapping roles of MTA and adenosine, we investigated the expression of $I L 6$, another important regulator of macrophage activation $(57,58)$ that has been reported to be upregulated in response to adenosine signaling (5963). We found that adenosine much more potently upregulated IL6 than did MTA, and that while inhibition of STAT3 decreased IL6 expression in the context of MTA treatment, STAT3 inhibition had no effect after adenosine treatment (Fig. 5F). Furthermore, adenosinemediated upregulation of IL6 expression was potentiated by $A_{2 \mathrm{~A}}$ receptor antagonist istradefylline, as well as by inhibition of CREB or C/EBP, while the effect of MTA was only potentiated by the C/EBP inhibitor, betulinic acid, suggesting there are different negative feedback signaling pathways for MTA and adenosine (Fig. 5G). Thus, while the effect of MTA and adenosine on IL6 expression again showed some overlap (both metabolites upregulated IL6, though adenosine to a greater extent, and the addition of C/EBP inhibition further increased IL6 expression in response to both), the dramatic differences in IL6 regulation in response to MTA or adenosine highlight the quantitative distinction in the degree to which different receptors and pathways are activated by these two metabolites.

The finding that adenosine upregulates both IL10 and IL6 expression while MTA stimulates only IL10 provides a potential explanation for the distinct gene expression patterns resulting from MTA or adenosine treatment (Fig. 5A and B). It is recognized that IL-10 has a more anti-inflammatory effect than IL-6, despite both cytokine receptors activating Jak1/STAT3 $(54,64,65)$. This difference in inflammatory signaling is thought to be due to feedback regulation of IL-6 signaling by STAT3induced Socs3 (65), whose expression was upregulated following both MTA and adenosine treatment in our model (Supporting Fig. S6E). IL-10 has been shown to be essential for the anti-inflammatory response, through its opposition of IL-6 and its role in suppressing inflammatory cytokines (66), thus raising the possibility that activation of $I L 10$ in response to MTA may potentiate the anti-inflammatory effect of adenosine receptor signaling.

Collectively these results suggest that MTA and adenosine each engage a distinct balance of adenosine receptor signaling, resulting in a divergent pathway activation and gene expression profiles (Fig. 6). This unique effect of MTA on macrophage M2 activation is not shared by adenosine, requires the adenosine $\mathrm{A}_{2 \mathrm{~B}}$ receptor, STAT3, and C/EBP, and indicates an immunosuppressive effect of MTA accumulation in MTAP deficient GBM.

\section{DISCUSSION}

Understanding and targeting the immunosuppressive mechanisms of GBM is a critical step toward improving treatment for this lethal cancer type (7). In this study, we provide multiple lines of evidence to link MTAP loss, one of the most common genetic/epigenetic events in GBM, to changes in the tumor immune microenvironment. We demonstrate using in vitro tumor models that MTAP deleted cells have a more antiinflammatory gene expression signature, and that this immunosuppressive state is recapitulated in the gene expression and immune infiltrate data from GBM patient samples. Loss of MTAP is expected to have profound impact on tumor cells, including conferring susceptibility to PRMT5 inhibition $(22,23)$ and reshaping the methylome landscape and identity of GBM cells (Hansen et al, submitted). Thus, it is not surprising that MTAP status also influences the expression of immune regulatory genes within this cell population. The type of differential gene expression analysis we performed on cultured tumor cells, without comprehensively considering non cell-autonomous effects on tumor 
immune infiltrates, is an obvious limitation. Nevertheless, findings from these in vitro models were supported by the results from GBM samples, including differential expression of immune regulatory genes and differential representation of immune cell types.

We discovered through our analysis of GBM samples that one of the cell types profoundly affected by MTAP status was the macrophage, with MTAP loss pushing macrophages toward alternative, immunesuppressive M2 polarization. Utilizing in vitro models we verified that the process of M2 polarization in this context is influenced by MTA signaling through the adenosine $\mathrm{A}_{2 \mathrm{~B}}$ receptor and is dependent on the activity of STAT3, ultimately resulting in upregulation of M2 marker genes Arg1, IL10, and Vegfa. This represents a unique mechanism of alternative activation and a potentially significant contribution to the immunosuppressive tumor microenvironment in GBM, which is known for an abundance of immunosuppressive tumor-associated macrophages.

It has previously been demonstrated that MTA can directly suppress the proliferation and function of $\mathrm{T}$ lymphocytes $(24,67)$. Our findings complement these studies by showing that MTA, which accumulates in MTAP-deficient tumor cells, can also influence innate immune cells. Further research involving in vivo, using orthotopic GBM models will be necessary to illuminate the functional interplay between MTAP loss and the function of innate immune cells in GBM, and how they collectively influence the adaptive immune characteristics within the tumor. One question raised by this study is what might be the long term impact of the uptake/accumulation of MTA (i.e., via nucleoside transporters) on the epigenomes and epiproteomes of immune cells, an aspect awaiting further investigation, though previous studies indicate this might play an important role (68-70). Furthermore, we note that the experimental results represent a limited view of the complex time scale of the signaling mechanisms and responses involved. Nevertheless, our findings are revealing, as they unambiguously demonstrate the rapid effect of adenosine receptor $A_{2 B}$ signaling initiated by MTA, in a manner distinct from adenosine, on the identity and functionality of macrophages, the most abundant immune cell type in GBM tumors (43).

Importantly, our finding that the macrophage response to MTA is distinct from the response to adenosine suggests that MTAP-deficient GBMs with aberrant MTA accumulation likely have an impact on the immune environment in a manner that is qualitatively and/or quantitatively different from tumors which simply accumulate adenosine as a mechanism of immune evasion $(71,72)$. Using in vitro models we found that MTA more potently stimulated expression of M2 macrophage marker genes Arg1, Vegfa, and Timp1 and that MTA and adenosine are both capable of upregulating IL10 expression through divergent pathways which eventually converge on the transcription factors C/EBP and STAT3, as inhibition of each was able to block upregulation of IL10 in response to either MTA or adenosine. IL-10 and IL-6 both engage receptors on the cell surface which activate the JAK-STAT signaling pathway. STAT3 is known to positively regulate Arg1, Vegfa, and Timp1, and we showed that inhibition of STAT3 completely eradicated the upregulation of these genes in response to MTA, confirming a dominant/ obligatory role of STAT3 as a mediator of MTA-stimulated M2 polarization. Additionally, the exclusive upregulation of IL10 expression by MTA, as opposed to combined IL6 and IL10 upregulation initiated by adenosine, is a potential explanation for why MTA results in such an antiinflammatory gene expression profile, in accordance with the reported opposing forces of IL-6 and IL-10 on STAT3 $(64,65)$ and the potent immunosuppressive effects of IL$10(66)$.

The reasons for the different effects of MTA and adenosine on the activation of macrophage marker genes remains unclear. One possible explanation is that these two metabolites engage the various adenosine receptors involved to a different extent. Adenosine is known to have the highest affinity for the $A_{1}$ and $A_{3}$ receptor subtypes, followed by $A_{2 A}$ receptors, and has much lower affinity for the $A_{2 B}$ receptor by about 50 -fold (73). Based on the clear impact of $A_{2 B}$ receptor antagonism in mitigating the effects of MTA (but not the effects of adenosine) in our model, one possibility is that MTA either more potently or more exclusively activates $A_{2 B}$ than does adenosine (Fig. 6), though it is likely that each metabolite exerts some degree of influence on all four adenosine receptor subtypes with varying affinities. In theory, and depending on cell type, the response to MTA or adenosine will include a summarization of purinergic signaling through a combination of these receptors. Activation of G-protein coupled adenosine $A_{2 A}$ and $A_{2 B}$ receptors invariably results in increased cAMP levels, but each receptor can couple with more than one type of $G$ protein (74) resulting in distinct combinations of downstream signaling pathways $(75,76)$. It is these types of subtle differences in adenosine receptor function which are likely responsible for the different outcomes following MTA or adenosine treatment in this model. Specifically, evidence from our macrophage model showing robust stimulation of IL6 expression by adenosine that is unaffected by inhibition of $A_{2 B} R$ and is augmented by inhibition of $A_{2 A} R$ is indicative of involvement of the $A_{2 A}$ receptor and also the $A_{1}$ receptor as likely contributors to the adenosine response in these cells. Though we did not specifically test the involvement of $A_{1}$ or $A_{3}$ receptors in our model, the $A_{1}$ receptor has been shown in HEK293 cells to activate the transcription factor NF-kB (77), a welldocumented regulator of IL6 expression (78-81). We found that inhibition of another transcription factor, 
C/EBP, which is activated downstream of the $A_{2 A}$ receptor, phenocopied $A_{2 A} R$ inhibition in further upregulating IL6 expression after adenosine treatment. NF-kB and C/EBP are known to physically associate with one another, resulting in inhibition of promoters with NF$\mathrm{kB}$ enhancer motifs (82). Thus, when considering the potential combinations of receptors involved in generating this response to adenosine, the $\mathrm{A}_{1 \mathrm{~A}}$ receptor could lead to activation of NF-kB, and the $A_{2 A} / A_{2 B}$ receptors could lead to activation of $C / E B P$. Inhibition of $\mathrm{A}_{2 \mathrm{~A}}$ receptors or C/EBP would then throw off the balance of these two signaling pathways to favor IL-6 upregulation through NF-kB. We found that MTA, on the other hand, has only a minimal effect on IL6 expression, which was increased only when combined with a C/EBP inhibitor, and not with a CREB inhibitor or $\mathrm{A}_{2 \mathrm{~A}}$ antagonist, supporting the idea that MTA signaling is predominantly mediated through the $\mathrm{A}_{2 \mathrm{~B}}$ receptor, which was required for the upregulation of the other M2 polarization gene, and which has been reported as capable of directly inhibiting NF-kB activation (83).

Overall, the complicated roles of adenosine in regulating inflammation, as well as its tumor-promoting functions, are beginning to be more widely recognized (84). Adenosine receptors and the adenosine-generating enzymes, CD39 and CD73, are being investigated as therapeutic targets, either through stimulating or countering the adenosine receptor signaling pathways in order to control pathogenic inflammation or treat advanced cancers (85-87). In GBM, adenosine (and upregulation of CD39 and CD73) has been shown to contribute to immunosuppression (88). Additionally, $\mathrm{A}_{2 \mathrm{~B}}$ receptor signaling has been shown to promote tumor metastasis and stimulate tumor angiogenesis $(89,90)$. Our finding that the effect of MTA on macrophage functionality is mediated by the adenosine $A_{2 B}$ receptor and is amenable to pharmacological intervention adds a new line of evidence to support the rationale of targeting $\mathrm{A}_{2 \mathrm{~B}}$ receptor signaling, in particular in MTAP-deficient GBMs. Development of MTAP-deficient, immunecompetent GBM models will be necessary for further investigating the effectiveness of this strategy in vivo. We speculate in the case of MTAP-null GBM, given the abundant presence of tumor-associated macrophages and the characteristic immunosuppressive microenvironment, that the effect of $A_{2 B}$ antagonists will be a particularly relevant area for investigation, with the potential to significantly impact tumor growth and augment immunotherapeutic interventions in MTAP-deleted GBM.

\section{MATERIALS AND METHODS}

\section{Cell lines and cell culture.}

RAW 264.7 and THP-1 macrophage cell lines were obtained from the Duke Cell culture Facility. BV-2 cells were a generous gift from Dr. Tso-Pang Yao. RAW 264.7 and BV-2 cells were maintained in DMEM with 4.5g/L L-glucose (Sigma Cat \#D6429) supplemented with $10 \%$ heat-inactivated FBS and anti-anti (antibiotic/antimycotic). THP-1 cells were cultured in RPMI 1640 with 10\% heat-inactivated FBS and anti-anti. CT-2A cells were a generous donation from Dr. Darrell Bigner. The cells were maintained in DMEM/F12 (Gibco Cat \#11330-032) supplemented with B-27 (Gibco Cat \#17504-044), EGF (Stemcell), and FGF (Stemcell) and grown in suspension. Primary tissue cultures were derived with consent from patient tumor samples obtained by the Duke Brain Tumor Center. These patient-derived cultures were maintained in human neural stem cell (NSC) media (STEMCELL, cat\# 05751), supplemented with EGF, FGF, and Heparin and plated onto laminin coated plates. All experiments were performed within the first 20 passages.

\section{Plasmid construction and generation of derivative cell populations.}

The CRISPR system was used for knockout of Mtap in CT-2A. Two double-stranded oligonucleotides that encode sgRNA targeting exon 1 and exon 3 of Mtap were cloned into the px552-pEASY plasmid. CT-2A cells were transfected simultaneously with sgRNA plasmid and the px458 plasmid containing cas9 and GFP. For transient plasmid transfection, plasmids (2 plasmids at 1:1 ratio for achieving the desired gene deletion/mutations) and Transfex (ATCC, cat\# ACS-4005) were mixed and used for cell transfection according to manufacturer's instructions. Three to four days after the transfection, green fluorescent protein-positive (GFP+) cells were sorted via fluorescence-activated cell sorting (BD FACSVantage SE cell sorter, Duke Cancer Institute) to obtain the GFP+ population. Sorted cells were plated at single-cell densities and allowed to expand for 21 days, at which point DNA was prepped from each colony to screen for a deletion in MTAP (exon 1-exon 3) using PCR amplification across the deleted region. sgRNA and primer sequences are shown in Supporting Material Table 1.

\section{In vitro macrophage polarization.}

Raw 264.7 cells were plated in a 12 well dish and stimulated with methylthioadenosine (MTA) (Cayman Cat \#15593) or adenosine (Sigma Cat \#A9251) for 12 hours, at which point they were collected for analysis. Cytokines IL4 (Peprotech Cat \#200-04) and IL-13 (Peprotech Cat \#200-13) were added within one hour of MTA/adenosine administration at a dose of $5 \mathrm{ng} / \mathrm{mL}$. THP-1 stimulation with MTA was identical to RAW 264.7 cells except that the cells were first differentiated using PMA (Cayman Cat \#10008014) for 24 hours, then cultured in fresh media for 24 hours prior to stimulation. To test the impact of $A_{2 B}$ and $A_{2 A}$ receptors on MTA- 
mediated macrophage polarization, $\mathrm{A}_{2 \mathrm{~A}} \mathrm{R}$ inhibitor Istradefylline (Selleckchem Cat \#S2790) or $\mathrm{A}_{2 \mathrm{~B}} \mathrm{R}$ inhibitor PSB0778 (Tocris Cat \#3199) were added simultaneously with MTA or adenosine, except in the indicated experiments where delayed administration of the $A_{2 B} R$ inhibitor was tested. To further explore downstream signaling pathways STAT3 inhibitor Stattic (Tocris Cat \# 2798), CREB inhibitor 666-15 (Tocris, Cat \#5661) and C/EBP inhibitor betulinic acid (Tocris Cat \#3906) were added at the time of MTA/adenosine administration. To test the effect of physiological accumulations of MTA from tumor cells, spent media from CT-2A parental or MTAP knockout cells was collected and added to the macrophage media in a 2:1 ratio and cells were plated for 12 hours prior to measuring response.

\section{Preparation of RNA and RT- qPCR.}

Total RNA was extracted using quick-RNA mini prep kit (Zymo Research, cat\# 11-328) following the manufacturer's protocols. Concentration of RNA was determined by Nanodrop Lite Spectrophotometer (Thermo Scientific). For gene expression analysis, reverse transcription was performed to convert total RNA into complementary DNA (cDNA) using the RNA to cDNA EcoDry Premix (Clontech, cat \#639547). Subsequently, real-time qPCR was performed following the aforementioned qPCR procedure. Each reaction included a cDNA template equivalent of $10 \mathrm{ng}$ of total RNA. The glyceraldehyde 3-phosphate dehydrogenase $(G A P D H)$ and beta-Actin genes were used as internal expression controls for RT-qPCR with reliable results. When beta Actin was used as the control amplicon the following program was followed: $95^{\circ} \mathrm{C}, 3$ minutes; 41 cycles of $95^{\circ} \mathrm{C} 10$ seconds and $68^{\circ} \mathrm{C} 20$ seconds, then a standard dissociation curve from $65^{\circ} \mathrm{C}$ to $95^{\circ} \mathrm{C}$ of 5 seconds/ 5 degree increment. When Gapdh was utilized as the internal control the following program was used: $95^{\circ} \mathrm{C}, 3$ minutes; 40 cycles of $95^{\circ} \mathrm{C} 10$ seconds, $60^{\circ} \mathrm{C} 20$ seconds, and $72^{\circ} \mathrm{C} 1$ second, then a standard dissociation curve from $65^{\circ} \mathrm{C}$ to $95^{\circ} \mathrm{C}$ of 5 seconds/ 5 degree increment.

\section{Oligos and primers.}

All oligos and primers used for the study were synthesized by Eton Bio and are listed in Supporting data Table 1. Quantitative PCR was performed using KAPA SYBR Fast 2x Universal master mix (KK4602) according to the manufacturer's protocols on a BIO-RAD CFX96 Real-Time System.

\section{Gene expression microarray.}

The RNA was extracted as described above. Samples were analyzed using the Affymetrix Human Genome U133 Plus 2.0 array according to the manufacturer's protocols by the Duke Sequencing and
Genomic Technologies Shared Resource. Data was analyzed using the Affymetrix Expression Console and Affymetrix Transcriptome Analysis Console v3.0 software.

\section{Pathway analysis.}

Pathway analysis was done using the DAVID 6.8 platform at david.ncifcrf.gov $(91,92)$. For pathway analysis of gene expression differences between in vitro samples and between patient cohorts, all genes found to be "significant" by the parameters defined in the manuscript were included in the analysis, with a maximum of 3000 genes allowed by DAVID (if more than 3,000 probes showed significantly different expression levels between the two populations, those with the highest difference were included).

\section{Gene Set Enrichment Analysis.}

Gene set enrichment analysis was performed using the GSEA 3.0 software as previously described. Custom gene sets were generated containing HLA genes and inflammatory signaling molecules. Gene sets are listed in supporting information table 2.

\section{Analysis of TCGA data.}

All TCGA data was downloaded from the online portal https://tcga-data.nci.nih.gov/docs/publications/tcga/ and through cbioportal.org $(33,34)$. The most recently published 2013 GBM data set was used for all analyses. For each analysis, the maximum number of complete cases available (confirmed IDH1/2 wildtype) were used unless otherwise stated, as IDH mutations are known to independently influence epigenetics and cellular differentiation. Analyses performed include gene expression (385 samples). We utilized MTAP expression levels to categorize patients rather than gene copy number because MTAP is known to be silenced epigenetically in a variety of cancer types (93-96), and our analysis (Hansen et al, submitted) of DNA methylation and gene expression data in patients suggests it can also be epigenetically silenced in GBM. To perform this analysis, samples were equally divided into quartiles based on MTAP expression and a $t$ Test was used to compare the "low" and "high" groups to find differences in gene expression between these two groups.

\section{Statistical analysis.}

Statistical tests (student's t test, ANOVA) were performed using Graphpad Prism. All experiments were repeated to ensure reproducibility of results. Unless otherwise indicated, pooled data from multiple experiments was used for each figure. A $P$ value cutoff of 0.05 was used to determine significance in all cases except where corrections were applied for larger data sets (ie. Bonferonni). 
Acknowledgements: We thank Ping Fan of the Duke Cancer Institute's Pharmacokinetic/Pharmacodynamic core laboratory for the LC-MS/MS metabolite analysis, and Heather Hemric, Laura-Leigh Rowlette, and Holly Dressman of the Duke Sequencing and Genomic Technologies Shared Resource for the Affymetrix array processing service.

Conflict of interest: The authors declare that they have no conflicts of interest with the contents of this article.

\section{Author Contributions:}

Conception and design: L.J. Hansen, Y. He

Methodology development: L.J. Hansen, R. Yang, Y. He

Data acquisition: L.J. Hansen, R. Yang, K. Woroniecka

Data analysis and interpretation: L.J. Hansen, K. Woroniecka, Y. He

Writing, reviewing, and revision of the manuscript: L.J. Hansen, R. Yang, K. Woroniecka, H. Yan, Y. He

Administrative, technical, or material support: H. Yan, Y. He

Study supervision: Y. He 


\section{REFERENCES}

1. Beatty, G. L., and Gladney, W. L. (2015) Immune escape mechanisms as a guide for cancer immunotherapy. Clinical cancer research : an official journal of the American Association for Cancer Research 21, 687-692

2. Motz, G. T., and Coukos, G. (2013) Deciphering and reversing tumor immune suppression. Immunity 39, 61-73

3. Lin, Y., and Okada, H. (2016) Cellular immunotherapy for malignant gliomas. Expert opinion on biological therapy 16, $1265-1275$

4. Reardon, D. A., Wucherpfennig, K. W., Freeman, G., Wu, C. J., Chiocca, E. A., Wen, P. Y., Curry, W. T., Jr., Mitchell, D. A., Fecci, P. E., Sampson, J. H., and Dranoff, G. (2013) An update on vaccine therapy and other immunotherapeutic approaches for glioblastoma. Expert review of vaccines 12, 597-615

5. McGranahan, T., Li, G., and Nagpal, S. (2017) History and current state of immunotherapy in glioma and brain metastasis. Therapeutic advances in medical oncology 9, 347-368

6. Stupp, R., Hegi, M. E., Mason, W. P., van den Bent, M. J., Taphoorn, M. J., Janzer, R. C., Ludwin, S. K., Allgeier, A., Fisher, B., Belanger, K., Hau, P., Brandes, A. A., Gijtenbeek, J., Marosi, C., Vecht, C. J., Mokhtari, K., Wesseling, P., Villa, S., Eisenhauer, E., Gorlia, T., Weller, M., Lacombe, D., Cairncross, J. G., Mirimanoff, R. O., European Organisation for, R., Treatment of Cancer Brain, T., Radiation Oncology, G., and National Cancer Institute of Canada Clinical Trials, G. (2009) Effects of radiotherapy with concomitant and adjuvant temozolomide versus radiotherapy alone on survival in glioblastoma in a randomised phase III study: 5-year analysis of the EORTCNCIC trial. The Lancet. Oncology 10, 459-466

7. Nduom, E. K., Weller, M., and Heimberger, A. B. (2015) Immunosuppressive mechanisms in glioblastoma. Neurooncology 17 Suppl 7, vii9-vii14

8. Woroniecka, K. I., Rhodin, K. E., Chongsathidkiet, P., Keith, K. A., and Fecci, P. E. (2018) T-Cell Dysfunction in Glioblastoma: Applying a New Framework. Clinical cancer research : an official journal of the American Association for Cancer Research

9. Woroniecka, K., Chongsathidkiet, P., Rhodin, K. E., Kemeny, H. R., Dechant, C. A., Farber, S. H., Elsamadicy, A. A., Cui, X., Koyama, S., Jackson, C. C., Hansen, L. J., Johanns, T. M., Sanchez-Perez, L., Chandramohan, V., Yu, Y. A., Bigner, D. D., Giles, A. J., Healy, P., Dranoff, G., Weinhold, K. J., Dunn, G. P., and Fecci, P. E. (2018) T Cell Exhaustion Signatures Vary with Tumor Type and are Severe in Glioblastoma. Clinical cancer research : an official journal of the American Association for Cancer Research

10. Brennan, C. W., Verhaak, R. G., McKenna, A., Campos, B., Noushmehr, H., Salama, S. R., Zheng, S., Chakravarty, D., Sanborn, J. Z., Berman, S. H., Beroukhim, R., Bernard, B., Wu, C. J., Genovese, G., Shmulevich, I., BarnholtzSloan, J., Zou, L., Vegesna, R., Shukla, S. A., Ciriello, G., Yung, W. K., Zhang, W., Sougnez, C., Mikkelsen, T., Aldape, K., Bigner, D. D., Van Meir, E. G., Prados, M., Sloan, A., Black, K. L., Eschbacher, J., Finocchiaro, G., Friedman, W., Andrews, D. W., Guha, A., lacocca, M., O'Neill, B. P., Foltz, G., Myers, J., Weisenberger, D. J., Penny, R., Kucherlapati, R., Perou, C. M., Hayes, D. N., Gibbs, R., Marra, M., Mills, G. B., Lander, E., Spellman, P., Wilson, R., Sander, C., Weinstein, J., Meyerson, M., Gabriel, S., Laird, P. W., Haussler, D., Getz, G., Chin, L., and Network, T. R. (2013) The somatic genomic landscape of glioblastoma. Cell 155, 462-477

11. Parsons, D. W., Jones, S., Zhang, X., Lin, J. C., Leary, R. J., Angenendt, P., Mankoo, P., Carter, H., Siu, I. M., Gallia, G. L., Olivi, A., McLendon, R., Rasheed, B. A., Keir, S., Nikolskaya, T., Nikolsky, Y., Busam, D. A., Tekleab, H., Diaz, L. A., Jr., Hartigan, J., Smith, D. R., Strausberg, R. L., Marie, S. K., Shinjo, S. M., Yan, H., Riggins, G. J., Bigner, D. D., Karchin, R., Papadopoulos, N., Parmigiani, G., Vogelstein, B., Velculescu, V. E., and Kinzler, K. W. (2008) An integrated genomic analysis of human glioblastoma multiforme. Science 321, 1807-1812

12. Verhaak, R. G., Hoadley, K. A., Purdom, E., Wang, V., Qi, Y., Wilkerson, M. D., Miller, C. R., Ding, L., Golub, T., Mesirov, J. P., Alexe, G., Lawrence, M., O'Kelly, M., Tamayo, P., Weir, B. A., Gabriel, S., Winckler, W., Gupta, S., Jakkula, L., Feiler, H. S., Hodgson, J. G., James, C. D., Sarkaria, J. N., Brennan, C., Kahn, A., Spellman, P. T., Wilson, R. K., Speed, T. P., Gray, J. W., Meyerson, M., Getz, G., Perou, C. M., Hayes, D. N., and Cancer Genome Atlas Research, N. (2010) Integrated genomic analysis identifies clinically relevant subtypes of glioblastoma characterized by abnormalities in PDGFRA, IDH1, EGFR, and NF1. Cancer cell 17, 98-110

13. Hodges, T. R., Ferguson, S. D., and Heimberger, A. B. (2016) Immunotherapy in glioblastoma: emerging options in precision medicine. CNS oncology 5, 175-186

14. Chen, C. F., Ruiz-Vega, R., Vasudeva, P., Espitia, F., Krasieva, T. B., de Feraudy, S., Tromberg, B. J., Huang, S., Garner, C. P., Wu, J., Hoon, D. S., and Ganesan, A. K. (2017) ATR Mutations Promote the Growth of Melanoma Tumors by Modulating the Immune Microenvironment. Cell reports 18, 2331-2342 
15. Coelho, M. A., de Carne Trecesson, S., Rana, S., Zecchin, D., Moore, C., Molina-Arcas, M., East, P., Spencer-Dene, B., Nye, E., Barnouin, K., Snijders, A. P., Lai, W. S., Blackshear, P. J., and Downward, J. (2017) Oncogenic RAS Signaling Promotes Tumor Immunoresistance by Stabilizing PD-L1 mRNA. Immunity 47, 1083-1099 e1086

16. Schumacher, T., Bunse, L., Pusch, S., Sahm, F., Wiestler, B., Quandt, J., Menn, O., Osswald, M., Oezen, I., Ott, M., Keil, M., Balss, J., Rauschenbach, K., Grabowska, A. K., Vogler, I., Diekmann, J., Trautwein, N., Eichmuller, S. B., Okun, J., Stevanovic, S., Riemer, A. B., Sahin, U., Friese, M. A., Beckhove, P., von Deimling, A., Wick, W., and Platten, M. (2014) A vaccine targeting mutant IDH1 induces antitumour immunity. Nature 512, 324-327

17. Kohanbash, G., Carrera, D. A., Shrivastav, S., Ahn, B. J., Jahan, N., Mazor, T., Chheda, Z. S., Downey, K. M., Watchmaker, P. B., Beppler, C., Warta, R., Amankulor, N. A., Herold-Mende, C., Costello, J. F., and Okada, H. (2017) Isocitrate dehydrogenase mutations suppress STAT1 and CD8+ T cell accumulation in gliomas. The Journal of clinical investigation 127, 1425-1437

18. Amankulor, N. M., Kim, Y., Arora, S., Kargl, J., Szulzewsky, F., Hanke, M., Margineantu, D. H., Rao, A., Bolouri, H., Delrow, J., Hockenbery, D., Houghton, A. M., and Holland, E. C. (2017) Mutant IDH1 regulates the tumorassociated immune system in gliomas. Genes \& development 31, 774-786

19. Zhang, X., Rao, A., Sette, P., Deibert, C., Pomerantz, A., Kim, W. J., Kohanbash, G., Chang, Y., Park, Y., Engh, J., Choi, J., Chan, T., Okada, H., Lotze, M., Grandi, P., and Amankulor, N. (2016) IDH mutant gliomas escape natural killer cell immune surveillance by downregulation of NKG2D ligand expression. Neuro-oncology 18, 1402-1412

20. Nobori, T., Karras, J. G., Della Ragione, F., Waltz, T. A., Chen, P. P., and Carson, D. A. (1991) Absence of methylthioadenosine phosphorylase in human gliomas. Cancer research 51, 3193-3197

21. Kamatani, N., and Carson, D. A. (1980) Abnormal regulation of methylthioadenosine and polyamine metabolism in methylthioadenosine phosphorylase-deficient human leukemic cell lines. Cancer Res 40, 4178-4182

22. Kryukov, G. V., Wilson, F. H., Ruth, J. R., Paulk, J., Tsherniak, A., Marlow, S. E., Vazquez, F., Weir, B. A., Fitzgerald, M. E., Tanaka, M., Bielski, C. M., Scott, J. M., Dennis, C., Cowley, G. S., Boehm, J. S., Root, D. E., Golub, T. R., Clish, C. B., Bradner, J. E., Hahn, W. C., and Garraway, L. A. (2016) MTAP deletion confers enhanced dependency on the PRMT5 arginine methyltransferase in cancer cells. Science 351, 1214-1218

23. Mavrakis, K. J., McDonald, E. R., 3rd, Schlabach, M. R., Billy, E., Hoffman, G. R., deWeck, A., Ruddy, D. A., Venkatesan, K., Yu, J., McAllister, G., Stump, M., deBeaumont, R., Ho, S., Yue, Y., Liu, Y., Yan-Neale, Y., Yang, G., Lin, F., Yin, H., Gao, H., Kipp, D. R., Zhao, S., McNamara, J. T., Sprague, E. R., Zheng, B., Lin, Y., Cho, Y. S., Gu, J., Crawford, K., Ciccone, D., Vitari, A. C., Lai, A., Capka, V., Hurov, K., Porter, J. A., Tallarico, J., Mickanin, C., Lees, E., Pagliarini, R., Keen, N., Schmelzle, T., Hofmann, F., Stegmeier, F., and Sellers, W. R. (2016) Disordered methionine metabolism in MTAP/CDKN2A-deleted cancers leads to dependence on PRMT5. Science 351, 12081213

24. Henrich, F. C., Singer, K., Poller, K., Bernhardt, L., Strobl, C. D., Limm, K., Ritter, A. P., Gottfried, E., Volkl, S., Jacobs, B., Peter, K., Mougiakakos, D., Dettmer, K., Oefner, P. J., Bosserhoff, A. K., Kreutz, M. P., Aigner, M., and Mackensen, A. (2016) Suppressive effects of tumor cell-derived 5'-deoxy-5'-methylthioadenosine on human T cells. Oncoimmunology 5, e1184802

25. Limm, K., Wallner, S., Milenkovic, V. M., Wetzel, C. H., and Bosserhoff, A. K. (2014) The metabolite 5'methylthioadenosine signals through the adenosine receptor $A 2 B$ in melanoma. European journal of cancer 50 , 2714-2724

26. Keyel, P. A., Romero, M., Wu, W., Kwak, D. H., Zhu, Q., Liu, X., and Salter, R. D. (2014) Methylthioadenosine reprograms macrophage activation through adenosine receptor stimulation. PloS one 9, e104210

27. Lathia, J. D., Mack, S. C., Mulkearns-Hubert, E. E., Valentim, C. L., and Rich, J. N. (2015) Cancer stem cells in glioblastoma. Genes \& development 29, 1203-1217

28. Benight, N. M., Stoll, B., Marini, J. C., and Burrin, D. G. (2012) Preventative oral methylthioadenosine is antiinflammatory and reduces DSS-induced colitis in mice. American journal of physiology. Gastrointestinal and liver physiology 303, G71-82

29. Moreno, B., Hevia, H., Santamaria, M., Sepulcre, J., Munoz, J., Garcia-Trevijano, E. R., Berasain, C., Corrales, F. J., Avila, M. A., and Villoslada, P. (2006) Methylthioadenosine reverses brain autoimmune disease. Annals of neurology 60, 323-334

30. Wang, L., Ko, E. R., Gilchrist, J. J., Pittman, K. J., Rautanen, A., Pirinen, M., Thompson, J. W., Dubois, L. G., Langley, R. J., Jaslow, S. L., Salinas, R. E., Rouse, D. C., Moseley, M. A., Mwarumba, S., Njuguna, P., Mturi, N., Wellcome Trust Case Control, C., Kenyan Bacteraemia Study, G., Williams, T. N., Scott, J. A., Hill, A. V., Woods, C. W., Ginsburg, G. S., Tsalik, E. L., and Ko, D. C. (2017) Human genetic and metabolite variation reveals that 
methylthioadenosine is a prognostic biomarker and an inflammatory regulator in sepsis. Science advances $\mathbf{3}$, e1602096

31. Mills, G. C., and Mills, J. S. (1985) Urinary excretion of methylthioadenosine in immunodeficient children. Clinica chimica acta; international journal of clinical chemistry 147, 15-23

32. Subramanian, A., Tamayo, P., Mootha, V. K., Mukherjee, S., Ebert, B. L., Gillette, M. A., Paulovich, A., Pomeroy, S. L., Golub, T. R., Lander, E. S., and Mesirov, J. P. (2005) Gene set enrichment analysis: a knowledge-based approach for interpreting genome-wide expression profiles. Proceedings of the National Academy of Sciences of the United States of America 102, 15545-15550

33. Gao, J., Aksoy, B. A., Dogrusoz, U., Dresdner, G., Gross, B., Sumer, S. O., Sun, Y., Jacobsen, A., Sinha, R., Larsson, E., Cerami, E., Sander, C., and Schultz, N. (2013) Integrative analysis of complex cancer genomics and clinical profiles using the cBioPortal. Science signaling 6 , pl1

34. Cerami, E., Gao, J., Dogrusoz, U., Gross, B. E., Sumer, S. O., Aksoy, B. A., Jacobsen, A., Byrne, C. J., Heuer, M. L., Larsson, E., Antipin, Y., Reva, B., Goldberg, A. P., Sander, C., and Schultz, N. (2012) The cBio cancer genomics portal: an open platform for exploring multidimensional cancer genomics data. Cancer discovery 2, 401-404

35. Newman, A. M., Liu, C. L., Green, M. R., Gentles, A. J., Feng, W., Xu, Y., Hoang, C. D., Diehn, M., and Alizadeh, A. A. (2015) Robust enumeration of cell subsets from tissue expression profiles. Nature methods 12, 453-457

36. Gentles, A. J., Newman, A. M., Liu, C. L., Bratman, S. V., Feng, W., Kim, D., Nair, V. S., Xu, Y., Khuong, A., Hoang, C. D., Diehn, M., West, R. B., Plevritis, S. K., and Alizadeh, A. A. (2015) The prognostic landscape of genes and infiltrating immune cells across human cancers. Nature medicine 21, 938-945

37. Chen, B., Khodadoust, M. S., Liu, C. L., Newman, A. M., and Alizadeh, A. A. (2018) Profiling Tumor Infiltrating Immune Cells with CIBERSORT. Methods in molecular biology 1711, 243-259

38. Newman, A. M., Gentles, A. J., Liu, C. L., Diehn, M., and Alizadeh, A. A. (2017) Data normalization considerations for digital tumor dissection. Genome biology 18, 128

39. Ceccarelli, M., Barthel, F. P., Malta, T. M., Sabedot, T. S., Salama, S. R., Murray, B. A., Morozova, O., Newton, Y., Radenbaugh, A., Pagnotta, S. M., Anjum, S., Wang, J., Manyam, G., Zoppoli, P., Ling, S., Rao, A. A., Grifford, M., Cherniack, A. D., Zhang, H., Poisson, L., Carlotti, C. G., Jr., Tirapelli, D. P., Rao, A., Mikkelsen, T., Lau, C. C., Yung, W. K., Rabadan, R., Huse, J., Brat, D. J., Lehman, N. L., Barnholtz-Sloan, J. S., Zheng, S., Hess, K., Rao, G., Meyerson, M., Beroukhim, R., Cooper, L., Akbani, R., Wrensch, M., Haussler, D., Aldape, K. D., Laird, P. W., Gutmann, D. H., Network, T. R., Noushmehr, H., lavarone, A., and Verhaak, R. G. (2016) Molecular Profiling Reveals Biologically Discrete Subsets and Pathways of Progression in Diffuse Glioma. Cell 164, 550-563

40. Charoentong, P., Finotello, F., Angelova, M., Mayer, C., Efremova, M., Rieder, D., Hackl, H., and Trajanoski, Z. (2017) Pan-cancer Immunogenomic Analyses Reveal Genotype-Immunophenotype Relationships and Predictors of Response to Checkpoint Blockade. Cell reports 18, 248-262

41. Lamb, L. S., Jr. (2009) Gammadelta T cells as immune effectors against high-grade gliomas. Immunologic research $45,85-95$

42. Noy, R., and Pollard, J. W. (2014) Tumor-associated macrophages: from mechanisms to therapy. Immunity 41, 49-61

43. Charles, N. A., Holland, E. C., Gilbertson, R., Glass, R., and Kettenmann, H. (2012) The brain tumor microenvironment. Glia 60, 502-514

44. Hasko, G., and Pacher, P. (2012) Regulation of macrophage function by adenosine. Arteriosclerosis, thrombosis, and vascular biology 32, 865-869

45. Csoka, B., Selmeczy, Z., Koscso, B., Nemeth, Z. H., Pacher, P., Murray, P. J., Kepka-Lenhart, D., Morris, S. M., Jr., Gause, W. C., Leibovich, S. J., and Hasko, G. (2012) Adenosine promotes alternative macrophage activation via $\mathrm{A} 2 \mathrm{~A}$ and $\mathrm{A} 2 \mathrm{~B}$ receptors. FASEB journal : official publication of the Federation of American Societies for Experimental Biology 26, 376-386

46. Ara, A. I., Xia, M., Ramani, K., Mato, J. M., and Lu, S. C. (2008) S-adenosylmethionine inhibits lipopolysaccharideinduced gene expression via modulation of histone methylation. Hepatology 47, 1655-1666

47. Koscso, B., Csoka, B., Kokai, E., Nemeth, Z. H., Pacher, P., Virag, L., Leibovich, S. J., and Hasko, G. (2013) Adenosine augments IL-10-induced STAT3 signaling in M2c macrophages. Journal of leukocyte biology 94, 13091315

48. Gordon, S. (2003) Alternative activation of macrophages. Nature reviews. Immunology 3, 23-35

49. Chawla, A. (2010) Control of macrophage activation and function by PPARs. Circulation research 106, 1559-1569 
50. Ferrante, C. J., Pinhal-Enfield, G., Elson, G., Cronstein, B. N., Hasko, G., Outram, S., and Leibovich, S. J. (2013) The adenosine-dependent angiogenic switch of macrophages to an M2-like phenotype is independent of interleukin4 receptor alpha (IL-4Ralpha) signaling. Inflammation 36, 921-931

51. Rebe, C., Vegran, F., Berger, H., and Ghiringhelli, F. (2013) STAT3 activation: A key factor in tumor immunoescape. Jak-Stat 2, e23010

52. Ruffell, D., Mourkioti, F., Gambardella, A., Kirstetter, P., Lopez, R. G., Rosenthal, N., and Nerlov, C. (2009) A CREB-C/EBPbeta cascade induces $\mathrm{M} 2$ macrophage-specific gene expression and promotes muscle injury repair. Proceedings of the National Academy of Sciences of the United States of America 106, 17475-17480

53. Vasquez-Dunddel, D., Pan, F., Zeng, Q., Gorbounov, M., Albesiano, E., Fu, J., Blosser, R. L., Tam, A. J., Bruno, T., Zhang, H., Pardoll, D., and Kim, Y. (2013) STAT3 regulates arginase-I in myeloid-derived suppressor cells from cancer patients. The Journal of clinical investigation 123, 1580-1589

54. Nakamura, R., Sene, A., Santeford, A., Gdoura, A., Kubota, S., Zapata, N., and Apte, R. S. (2015) IL10-driven STAT3 signalling in senescent macrophages promotes pathological eye angiogenesis. Nature communications 6, 7847

55. Hasita, H., Komohara, Y., Okabe, H., Masuda, T., Ohnishi, K., Lei, X. F., Beppu, T., Baba, H., and Takeya, M. (2010) Significance of alternatively activated macrophages in patients with intrahepatic cholangiocarcinoma. Cancer science 101, 1913-1919

56. Brenner, S., Prosch, S., Schenke-Layland, K., Riese, U., Gausmann, U., and Platzer, C. (2003) cAMP-induced Interleukin-10 promoter activation depends on CCAAT/enhancer-binding protein expression and monocytic differentiation. The Journal of biological chemistry 278, 5597-5604

57. Wang, Q., He, Z., Huang, M., Liu, T., Wang, Y., Xu, H., Duan, H., Ma, P., Zhang, L., Zamvil, S. S., Hidalgo, J., Zhang, Z., O'Rourke, D. M., Dahmane, N., Brem, S., Mou, Y., Gong, Y., and Fan, Y. (2018) Vascular niche IL-6 induces alternative macrophage activation in glioblastoma through HIF-2alpha. Nature communications 9, 559

58. Mauer, J., Chaurasia, B., Goldau, J., Vogt, M. C., Ruud, J., Nguyen, K. D., Theurich, S., Hausen, A. C., Schmitz, J., Bronneke, H. S., Estevez, E., Allen, T. L., Mesaros, A., Partridge, L., Febbraio, M. A., Chawla, A., Wunderlich, F. T., and Bruning, J. C. (2014) Signaling by IL-6 promotes alternative activation of macrophages to limit endotoxemia and obesity-associated resistance to insulin. Nature immunology 15, 423-430

59. Zhang, L., Franchini, M., Wehrli Eser, M., and Dip, R. (2012) Enhanced IL-6 transcriptional response to adenosine receptor ligands in horses with lower airway inflammation. Equine veterinary journal 44, 81-87

60. Schwaninger, M., Neher, M., Viegas, E., Schneider, A., and Spranger, M. (1997) Stimulation of interleukin-6 secretion and gene transcription in primary astrocytes by adenosine. Journal of neurochemistry 69, 1145-1150

61. Schwaninger, M., Petersen, N., Prinz, S., Sallmann, S., Neher, M., and Spranger, M. (2000) Adenosine-induced expression of interleukin-6 in astrocytes through protein kinase A and NF-IL-6. Glia 31, 51-58

62. Fiebich, B. L., Akundi, R. S., Biber, K., Hamke, M., Schmidt, C., Butcher, R. D., van Calker, D., and Willmroth, F. (2005) IL-6 expression induced by adenosine A2b receptor stimulation in U373 MG cells depends on p38 mitogen activated kinase and protein kinase C. Neurochemistry international 46, 501-512

63. Rees, D. A., Lewis, B. M., Lewis, M. D., Francis, K., Scanlon, M. F., and Ham, J. (2003) Adenosine-induced IL-6 expression in pituitary folliculostellate cells is mediated via A2b adenosine receptors coupled to PKC and p38 MAPK. British journal of pharmacology 140, 764-772

64. Braun, D. A., Fribourg, M., and Sealfon, S. C. (2013) Cytokine response is determined by duration of receptor and signal transducers and activators of transcription 3 (STAT3) activation. The Journal of biological chemistry 288, 2986-2993

65. Niemand, C., Nimmesgern, A., Haan, S., Fischer, P., Schaper, F., Rossaint, R., Heinrich, P. C., and Muller-Newen, G. (2003) Activation of STAT3 by IL- 6 and IL-10 in primary human macrophages is differentially modulated by suppressor of cytokine signaling 3. Journal of immunology 170, 3263-3272

66. Hutchins, A. P., Diez, D., and Miranda-Saavedra, D. (2013) The IL-10/STAT3-mediated anti-inflammatory response: recent developments and future challenges. Briefings in functional genomics 12, 489-498

67. Vandenbark, A. A., Ferro, A. J., and Barney, C. L. (1980) Inhibition of lymphocyte transformation by a naturally occurring metabolite: 5'-methylthioadenosine. Cellular immunology 49, 26-33

68. Richard, S., Morel, M., and Cleroux, P. (2005) Arginine methylation regulates IL-2 gene expression: a role for protein arginine methyltransferase 5 (PRMT5). The Biochemical journal 388, 379-386

69. Bigaud, E., and Corrales, F. J. (2016) Methylthioadenosine (MTA) Regulates Liver Cells Proteome and Methylproteome: Implications in Liver Biology and Disease. Molecular \& cellular proteomics : MCP 15, 14981510 
70. Bonham, K., Hemmers, S., Lim, Y. H., Hill, D. M., Finn, M. G., and Mowen, K. A. (2010) Effects of a novel arginine methyltransferase inhibitor on T-helper cell cytokine production. The FEBS journal 277, 2096-2108

71. Morello, S., Pinto, A., Blandizzi, C., and Antonioli, L. (2016) Myeloid cells in the tumor microenvironment: Role of adenosine. Oncoimmunology 5, e1108515

72. Ohta, A. (2016) A Metabolic Immune Checkpoint: Adenosine in Tumor Microenvironment. Frontiers in immunology 7, 109

73. Fredholm, B. B., Irenius, E., Kull, B., and Schulte, G. (2001) Comparison of the potency of adenosine as an agonist at human adenosine receptors expressed in Chinese hamster ovary cells. Biochemical pharmacology 61, 443-448

74. Fredholm, B. B., AP, I. J., Jacobson, K. A., Klotz, K. N., and Linden, J. (2001) International Union of Pharmacology. XXV. Nomenclature and classification of adenosine receptors. Pharmacological reviews 53, 527-552

75. Chen, J. F., Lee, C. F., and Chern, Y. (2014) Adenosine receptor neurobiology: overview. International review of neurobiology 119, 1-49

76. Antonioli, L., Blandizzi, C., Pacher, P., and Hasko, G. (2013) Immunity, inflammation and cancer: a leading role for adenosine. Nature reviews. Cancer 13, 842-857

77. Liu, A. M., and Wong, Y. H. (2004) G16-mediated activation of nuclear factor kappaB by the adenosine A1 receptor involves c-Src, protein kinase C, and ERK signaling. The Journal of biological chemistry 279, 5319653204

78. Yoon, S., Woo, S. U., Kang, J. H., Kim, K., Shin, H. J., Gwak, H. S., Park, S., and Chwae, Y. J. (2012) NF-kappaB and STAT3 cooperatively induce IL6 in starved cancer cells. Oncogene 31, 3467-3481

79. Brasier, A. R. (2010) The nuclear factor-kappaB-interleukin-6 signalling pathway mediating vascular inflammation. Cardiovascular research 86, 211-218

80. Matsusaka, T., Fujikawa, K., Nishio, Y., Mukaida, N., Matsushima, K., Kishimoto, T., and Akira, S. (1993) Transcription factors NF-IL6 and NF-kappa B synergistically activate transcription of the inflammatory cytokines, interleukin 6 and interleukin 8. Proceedings of the National Academy of Sciences of the United States of America 90, 10193-10197

81. McFarland, B. C., Hong, S. W., Rajbhandari, R., Twitty, G. B., Jr., Gray, G. K., Yu, H., Benveniste, E. N., and Nozell, S. E. (2013) NF-kappaB-induced IL-6 ensures STAT3 activation and tumor aggressiveness in glioblastoma. PloS one 8, e78728

82. Stein, B., Cogswell, P. C., and Baldwin, A. S., Jr. (1993) Functional and physical associations between NF-kappa B and C/EBP family members: a Rel domain-bZIP interaction. Molecular and cellular biology 13, 3964-3974

83. Sun, Y., Duan, Y., Eisenstein, A. S., Hu, W., Quintana, A., Lam, W. K., Wang, Y., Wu, Z., Ravid, K., and Huang, P. (2012) A novel mechanism of control of NFkappaB activation and inflammation involving A2B adenosine receptors. Journal of cell science 125, 4507-4517

84. Hasko, G., and Cronstein, B. (2013) Regulation of inflammation by adenosine. Frontiers in immunology 4, 85 85. Hay, C. M., Sult, E., Huang, Q., Mulgrew, K., Fuhrmann, S. R., McGlinchey, K. A., Hammond, S. A., Rothstein, R., Rios-Doria, J., Poon, E., Holoweckyj, N., Durham, N. M., Leow, C. C., Diedrich, G., Damschroder, M., Herbst, R., Hollingsworth, R. E., and Sachsenmeier, K. F. (2016) Targeting CD73 in the tumor microenvironment with MEDI9447. Oncoimmunology 5, e1208875

86. Silverman, M. H., Strand, V., Markovits, D., Nahir, M., Reitblat, T., Molad, Y., Rosner, I., Rozenbaum, M., Mader, R., Adawi, M., Caspi, D., Tishler, M., Langevitz, P., Rubinow, A., Friedman, J., Green, L., Tanay, A., Ochaion, A., Cohen, S., Kerns, W. D., Cohn, I., Fishman-Furman, S., Farbstein, M., Yehuda, S. B., and Fishman, P. (2008) Clinical evidence for utilization of the $A 3$ adenosine receptor as a target to treat rheumatoid arthritis: data from a phase II clinical trial. The Journal of rheumatology 35, 41-48

87. Chen, J. F., Eltzschig, H. K., and Fredholm, B. B. (2013) Adenosine receptors as drug targets--what are the challenges? Nature reviews. Drug discovery 12, 265-286

88. Xu, S., Shao, Q. Q., Sun, J. T., Yang, N., Xie, Q., Wang, D. H., Huang, Q. B., Huang, B., Wang, X. Y., Li, X. G., and Qu, $X$. (2013) Synergy between the ectoenzymes CD39 and CD73 contributes to adenosinergic immunosuppression in human malignant gliomas. Neuro-oncology 15, 1160-1172

89. Sorrentino, C., Miele, L., Porta, A., Pinto, A., and Morello, S. (2015) Myeloid-derived suppressor cells contribute to $\mathrm{A} 2 \mathrm{~B}$ adenosine receptor-induced VEGF production and angiogenesis in a mouse melanoma model.

Oncotarget 6, 27478-27489

90. Desmet, C. J., Gallenne, T., Prieur, A., Reyal, F., Visser, N. L., Wittner, B. S., Smit, M. A., Geiger, T. R., Laoukili, J., Iskit, S., Rodenko, B., Zwart, W., Evers, B., Horlings, H., Ajouaou, A., Zevenhoven, J., van Vliet, M., Ramaswamy, 
S., Wessels, L. F., and Peeper, D. S. (2013) Identification of a pharmacologically tractable Fra-1/ADORA2B axis promoting breast cancer metastasis. Proceedings of the National Academy of Sciences of the United States of America 110, 5139-5144

91. Huang da, W., Sherman, B. T., and Lempicki, R. A. (2009) Systematic and integrative analysis of large gene lists using DAVID bioinformatics resources. Nature protocols 4, 44-57

92. Huang da, W., Sherman, B. T., and Lempicki, R. A. (2009) Bioinformatics enrichment tools: paths toward the comprehensive functional analysis of large gene lists. Nucleic acids research 37, 1-13

93. Behrmann, I., Wallner, S., Komyod, W., Heinrich, P. C., Schuierer, M., Buettner, R., and Bosserhoff, A. K. (2003) Characterization of methylthioadenosin phosphorylase (MTAP) expression in malignant melanoma. The American journal of pathology 163, 683-690

94. Hellerbrand, C., Muhlbauer, M., Wallner, S., Schuierer, M., Behrmann, I., Bataille, F., Weiss, T., Scholmerich, J., and Bosserhoff, A. K. (2006) Promoter-hypermethylation is causing functional relevant downregulation of methylthioadenosine phosphorylase (MTAP) expression in hepatocellular carcinoma. Carcinogenesis 27, 64-72

95. Ishii, M., Nakazawa, K., Wada, H., Nishioka, J., Nakatani, K., Yamada, Y., Kamihira, S., Kusunoki, M., and Nobori, T. (2005) Methylthioadenosine phosphorylase gene is silenced by promoter hypermethylation in human lymphoma cell line DHL-9: another mechanism of enzyme deficiency. International journal of oncology 26, 985991

96. Leal, M., Lima, E., Silva, P., Assumpcao, P., Calcagno, D., Payao, S., Burbano, R. R., and Smith, M. (2007) Promoter hypermethylation of CDH1, FHIT, MTAP and PLAGL1 in gastric adenocarcinoma in individuals from Northern Brazil. World journal of gastroenterology 13, 2568-2574 


\section{FOOTNOTES}

This work was supported by a National Cancer Institute National Research Service Award (F30CA206336; L.J.H), a National Comprehensive Cancer Network Young Investigator Award (Y.H.), and the National Institute Of Neurological Disorders And Stroke of the National Institutes of Health, Award Number R01NS101074 (Y.H). This work was also supported by funding from the National Institutes of Health Duke SPORE in Brain Cancer (P50 CA190991), as well as the Circle of Service Foundation (Y.H) and the Southeastern Brain Tumor Foundation (Y.H).

The abbreviations used are: MTA, methylthioadenosine; MTAP, methylthioadenosine phosphorylase; GBM, glioblastoma; RT-qPCR, reverse transcription quantitative polymerase chain reaction; B. Acid, Betulinic Acid; LC-MS/MS, Liquid chromatography tandem mass spectrometry. 
bioRxiv preprint doi: https://doi.org/10.1101/329664; this version posted May 24,2018 . The copyright holder for this preprint (which was not certified by peer review) is the author/funder. All rights reserved. No reuse allowed without permission.

\section{FIGURES}

A

\begin{tabular}{|l|c|}
\hline \multicolumn{1}{|c|}{$\begin{array}{c}\text { Downregulated KEGG } \\
\text { Pathways }\end{array}$} & $\begin{array}{c}\text { Benjamini } \\
\text { Hochberg } \\
\text { P-Value }\end{array}$ \\
\hline Toxoplasmosis & $1.8 \mathrm{E}-4$ \\
Graft-versus-host disease & $1.2 \mathrm{E}-3$ \\
Antigen processing and presentation & $9.4 \mathrm{E}-4$ \\
Allograft rejection & $1.3 \mathrm{E}-3$ \\
Autoimmune thyroid disease & $1.3 \mathrm{E}-3$ \\
Type I diabetes mellitus & $2.1 \mathrm{E}-3$ \\
Asthma & $2.1 \mathrm{E}-3$ \\
Cell adhesion molecules (CAMs) & $3.8 \mathrm{E}-3$ \\
Rheumatoid Arthritis & $5.6 \mathrm{E}-3$ \\
Leishmaniosis & $5.8 \mathrm{E}-3$ \\
Viral myocarditis & $7.5 \mathrm{E}-3$ \\
Tuberculosis & $1.8 \mathrm{E}-2$ \\
Inflammatory bowel disease & $1.4 \mathrm{E}-2$ \\
Influenza A & $4.3 \mathrm{E}-2$ \\
\hline
\end{tabular}

D

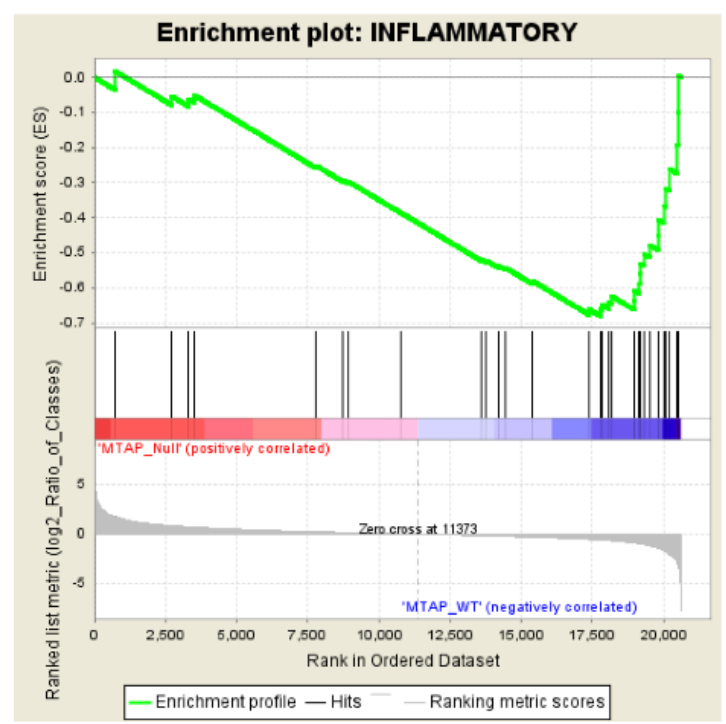

B

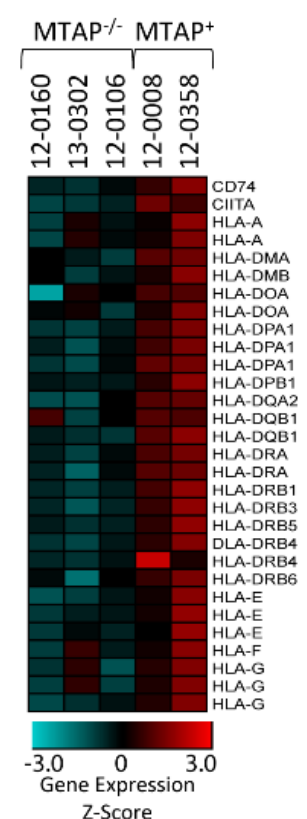

$E$

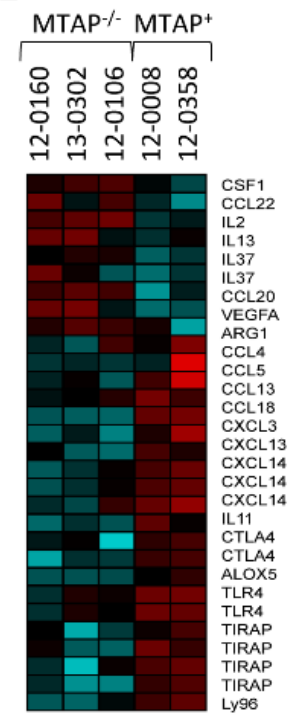

C

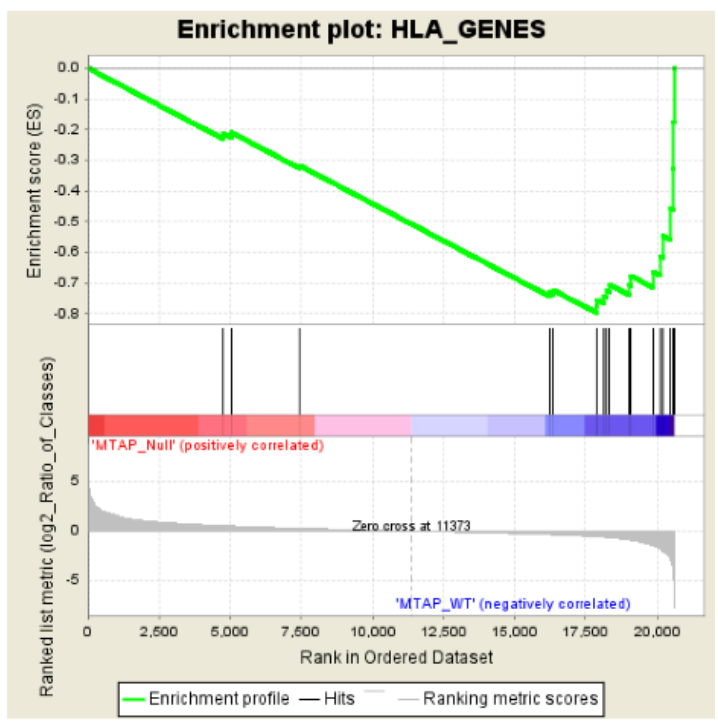

Figure 1. MTAP loss is correlated with downregulated inflammatory genes in GBM cells. (A) DAVID pathway analysis of 3,000 most downregulated genes in MTAP null cells compared to MTAP expressing cells reveals downregulated pathways related to inflammatory processes. (B) Heatmap showing expression of HLA genes is downregulated in MTAP null patient-derived GBM cell lines compared to MTAP WT cell lines. All transcripts with t test $P$ value $<0.05$ comparing the MTAP deleted and MTAP WT cell lines are included. 17/25 HLA transcripts are significantly downregulated (29 unique probes). No HLA transcripts are significantly upregulated in MTAP deleted cells. (C) Gene set enrichment analysis using a list of all HLA genes in the Affymetrix 2.0 plus microarray demonstrates significant enrichment of HLA genes in MTAP WT compared to MTAP deleted cell lines, Normalized Enrichment Score $=-2.18$, FDR q-value < 0.001. (D) Pathway analysis using a list of inflammatory cytokines (see supporting data for gene set) demonstrates enrichment of inflammatory gene expression in MTAP WT compared to MTAP deleted cell lines, Normalized Enrichment Score = -2.12, FDR q-value $<0.001$. (E) Heatmap comparing expression of individual transcripts between the MTAP deleted and MTAP WT cell lines. 
A

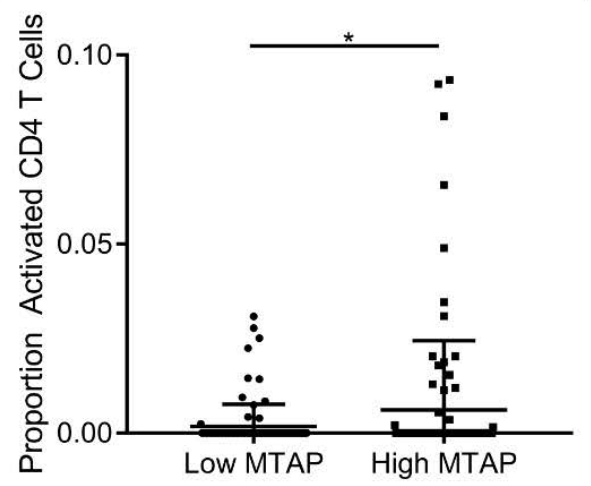

B

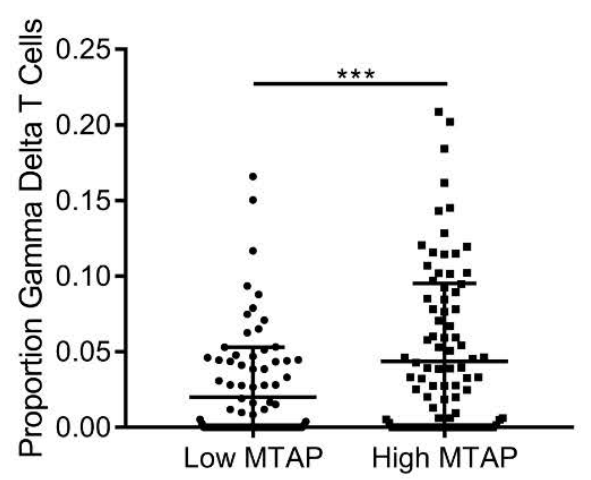

C

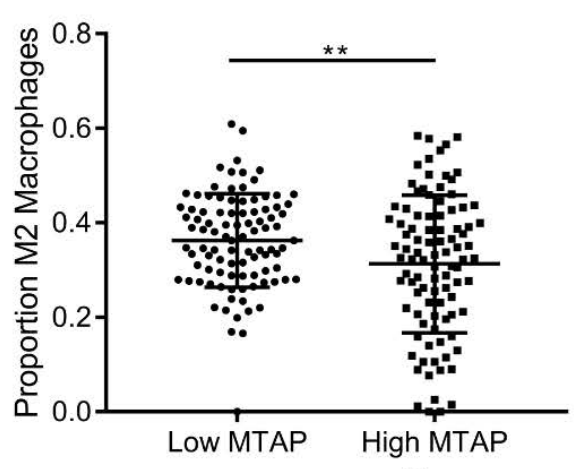

E

D

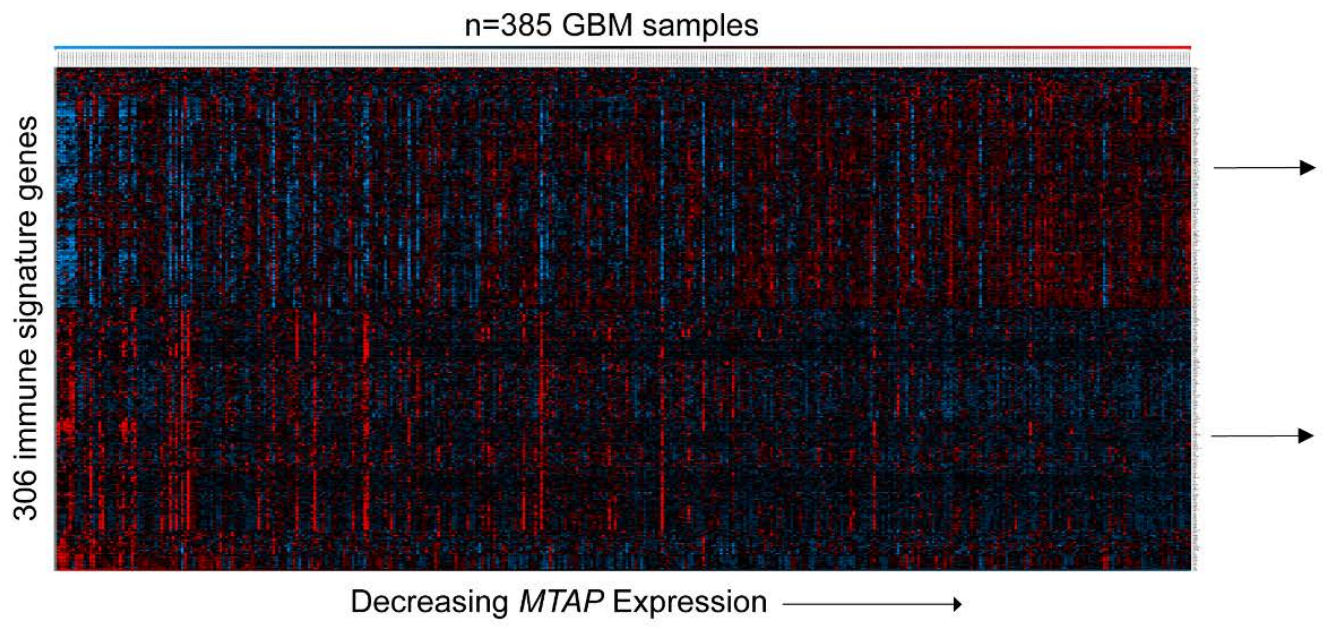

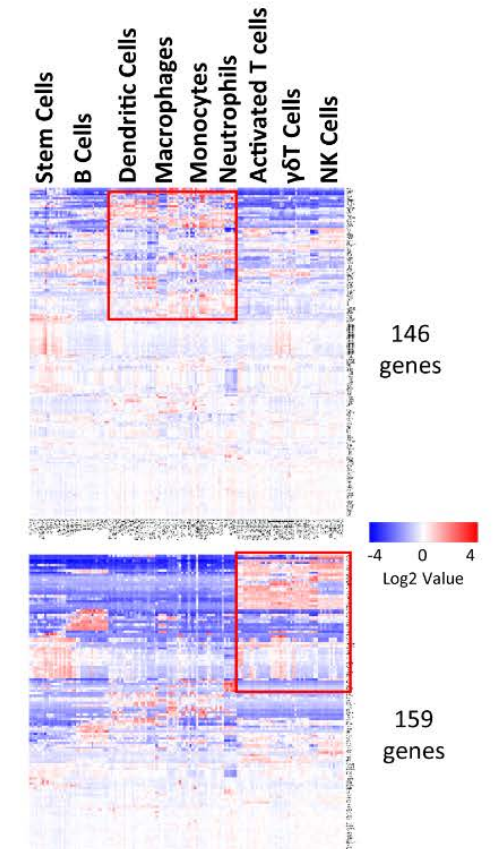

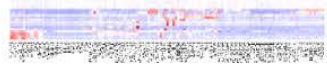

Figure 2. MTAP loss is correlated with an immunosuppressive gene signature in GBM samples. (A) Comparison of upper and lower MTAP expression quartiles ( $\mathrm{n}=96$ each category) using CIBERSORT analysis of GBM gene expression microarray data shows lower activated CD4 T cells in tumors with low MTAP expression. (B) GBM samples with the lowest quartile MTAP expression have fewer gamma delta T cells. (C) GBM samples with low MTAP expression have higher average proportions of M2 macrophages, $n=96$ each category. (D) Heatmap showing expression of 306 immune signature genes that are differentially expressed between the lower and upper MTAP expression quartiles in GBM patients. The gene list was derived from 782 immune-specific genes identified by Charoentong et al. Only 641 of the 782 genes were contained in the GBM microarray data set. Of the 641 genes in the GBM dataset, 306 genes were differentially expressed based on MTAP status, and were included in the heatmap. (E) Clustered gene sets from (D) were analyzed using data from the immunologic genome project (https://www.immgen.org), which uses a compendium of microarray data (366 microarrays/37 studies) from specific immune cell types to display which immune cells express the genes of interest. Clusters representing different immune cell types are marked at the top. Genes expressed in the low MTAP samples are more representative of macrophages, monocytes, dendritic cells, while genes expressed in high MTAP samples are more representative of activated CD4 cells, gamma delta $(\gamma \delta) \mathrm{T}$ cells, and natural killer $(\mathrm{NK})$ cells. $t$ test $P$ value * $\mathrm{P}<0.05, * * \mathrm{P}<0.005, * * * \mathrm{P}<0.0005$. 
A

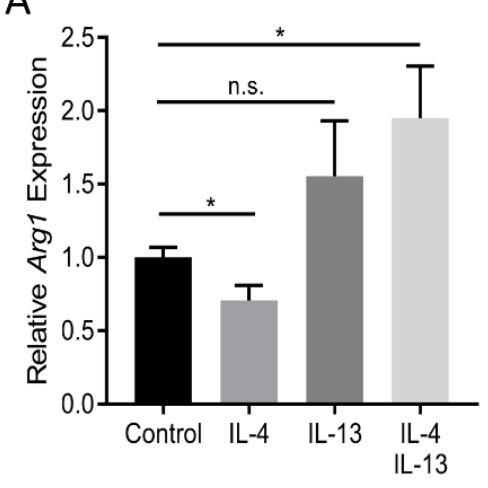

B
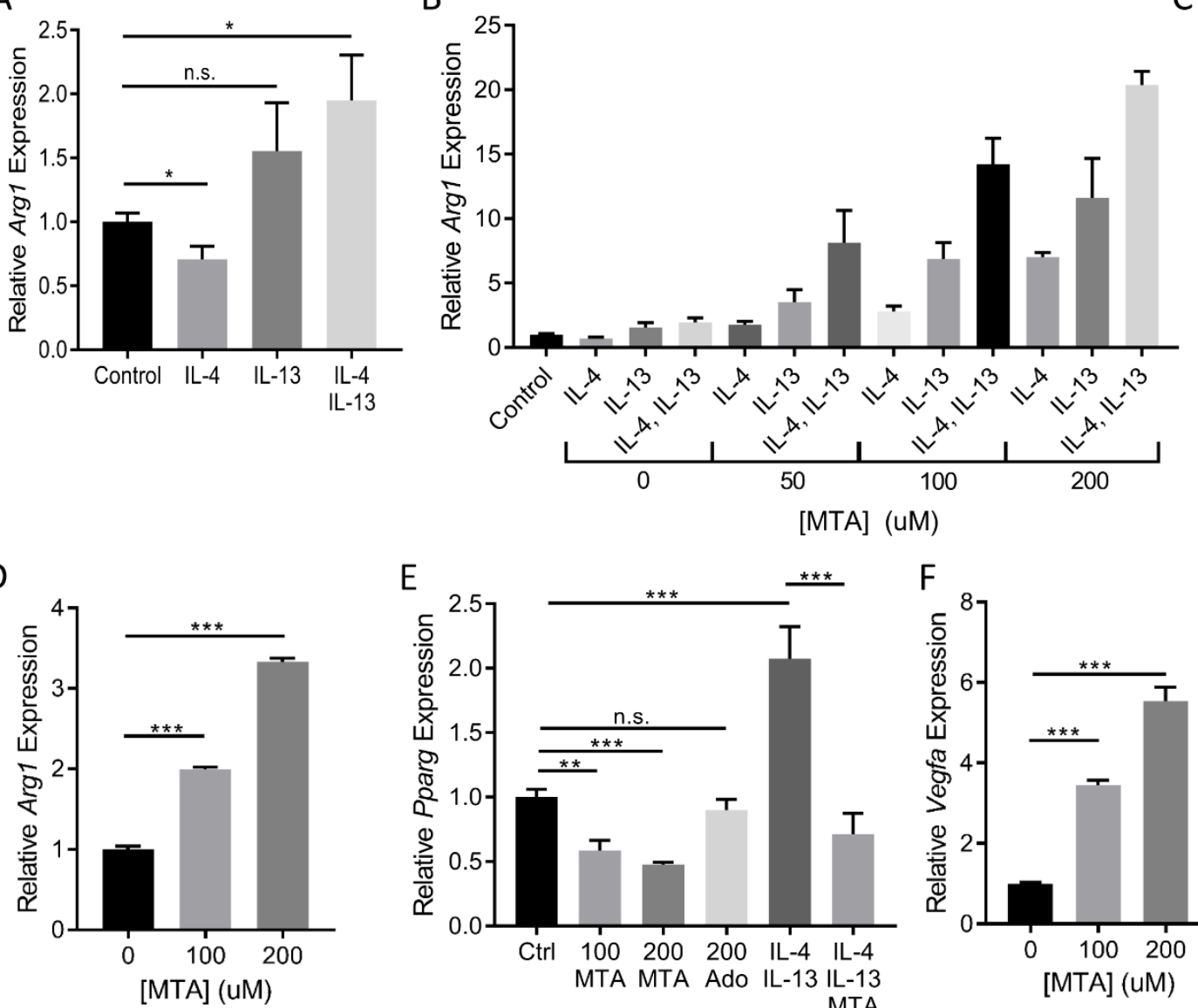

$\mathrm{E}$

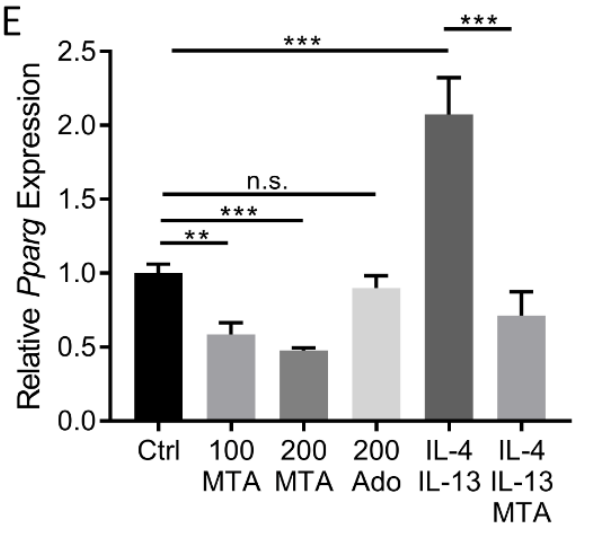

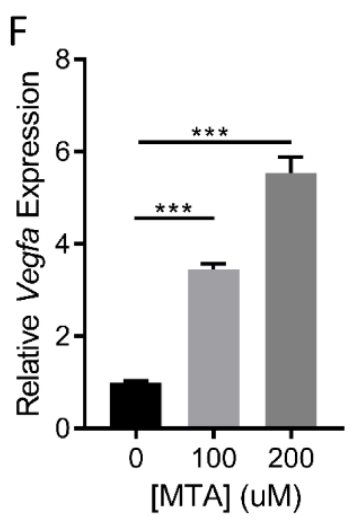

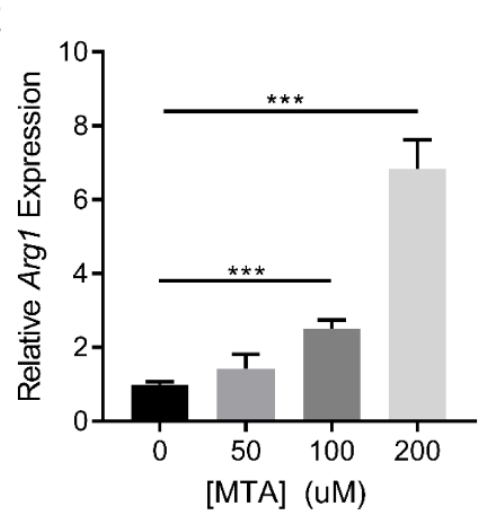

G

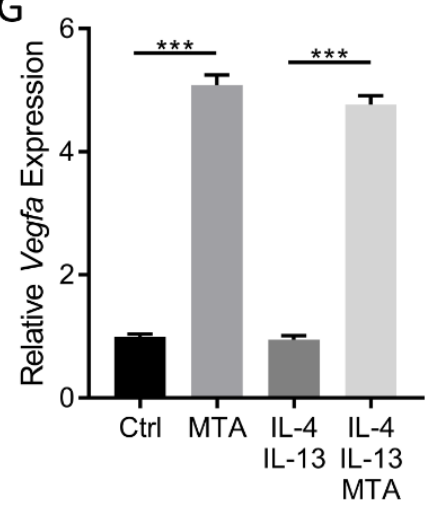

$\mathrm{H}$

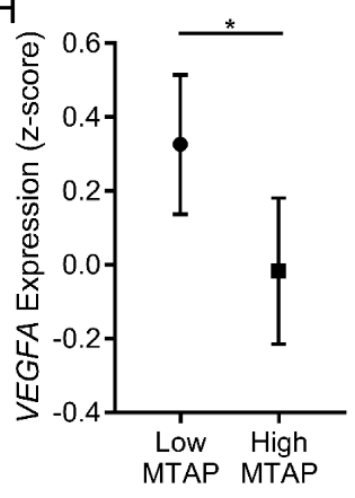

I

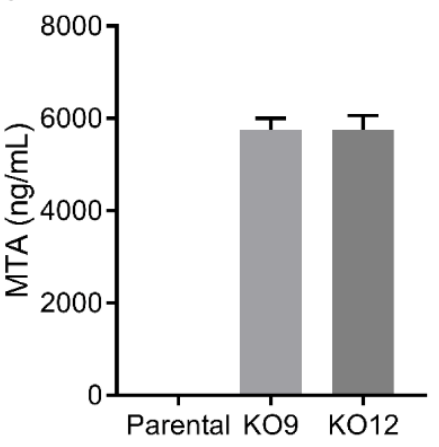

J

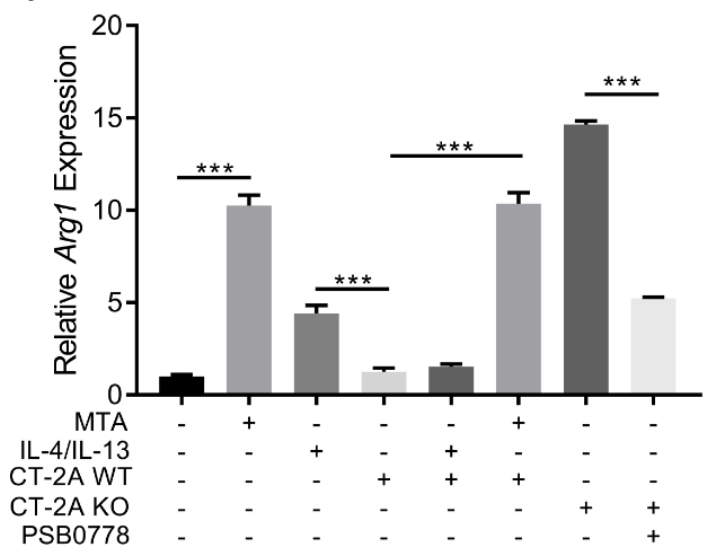

Figure 3. MTA promotes upregulation of M2 macrophage marker genes. (A) RAW 264.7 cells were treated with IL-4 and IL-13 individually or in combination ( $\mathrm{ng} / \mathrm{mL}$ for each cytokine) for 12 hours before total RNA was prepared for Arg1 expression analysis (all gene expression was measured by RT-qPCR. (B) RAW 264.7 cells were treated with the indicated cytokines as in (A), together with different doses of MTA, after which relative Arg1 expression was determined as above. (C) RAW 264.7 or (D) BV-2 cells were treated with different doses of MTA for 12 hours and Arg1 expression was measured. (E-G) RAW 264.7 cells were treated with the indicated cytokines with or without MTA for 12 hours, and total RNA was isolated for measuring expression of (E) Pparg and (F, G) Vegfa. Ado=adenosine. (H) TCGA human GBM microarray data were used for analyzing VEGFA expression in tumors with low or high MTAP expression, $\mathrm{n}=96$ patients per group. (I) MTA was measured in spent cell culture media from CT-2A parental and MTAP knockout cell lines using liquid chromatography tandem mass spectrometry (LC-MS/MS). (J) Raw 264.7 cells were exposed to media collected from parental or MTAP knockout CT-2A cells for 12 hours before Arg1 gene expression was measured by RTqPCR. All experiments were repeated independently. All statistical comparisons were performed using an unpaired student's t-test; $*=P<0.05, * *=P<0.005$, *** $=P<5 \times 10^{-4}$, n.s. $=$ not significant. 
A
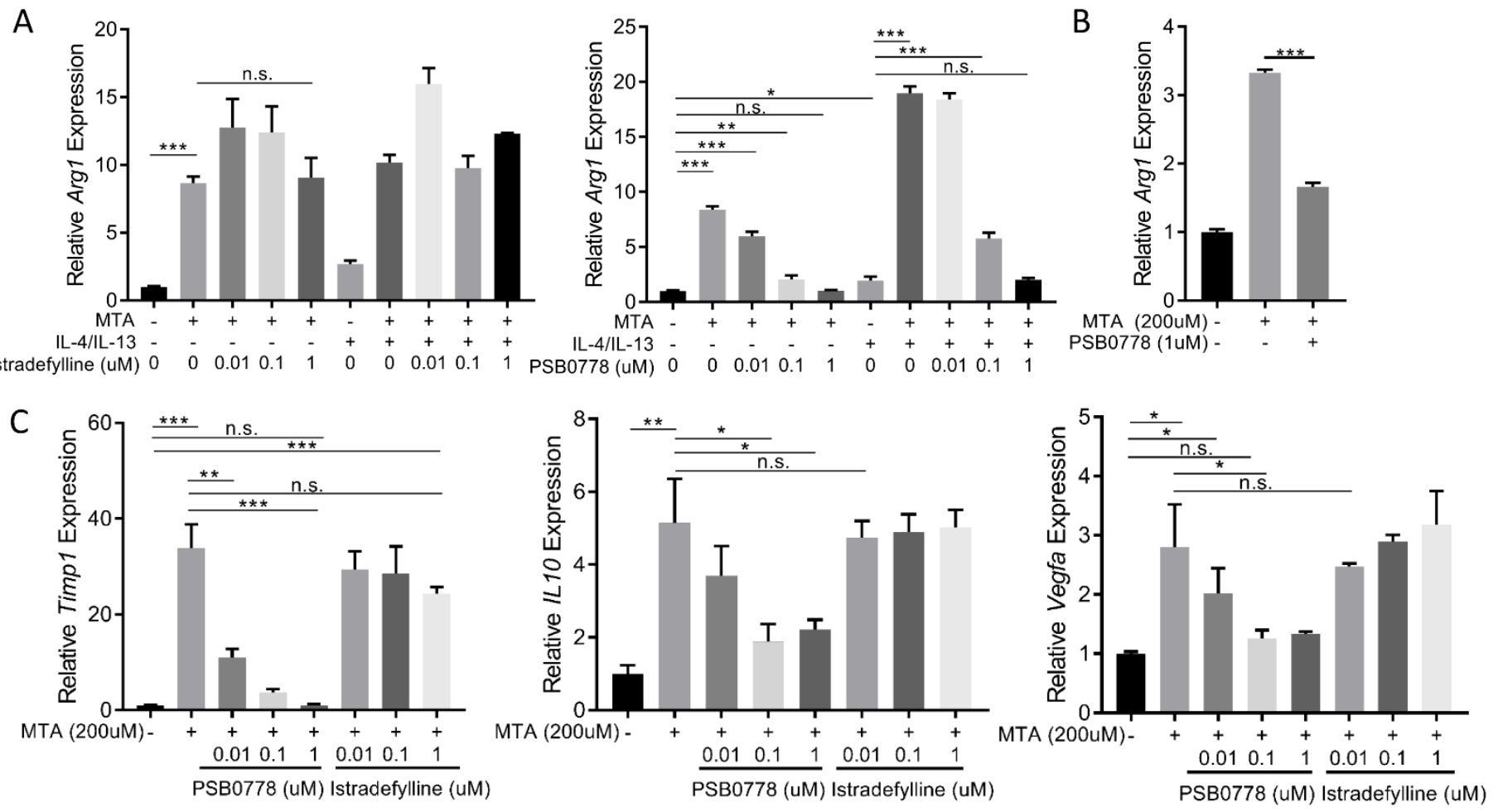

D
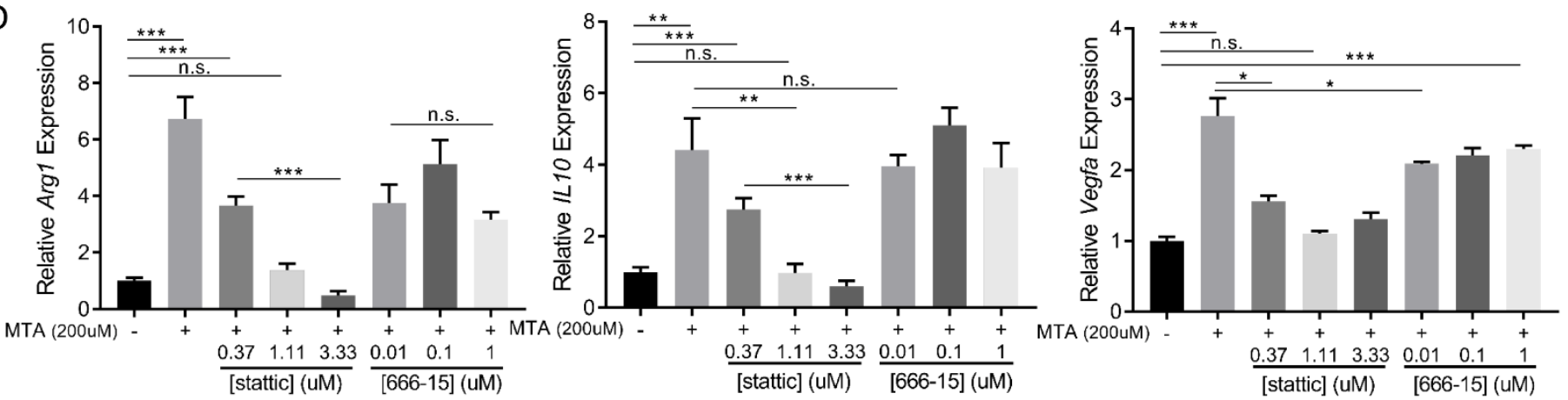

Figure 4. The impact of MTA on M2 macrophage marker genes is blocked by inhibition of the $A_{2 B}$ adenosine receptor and Stat3. (A) RAW 264.7 cells were treated with MTA and/or IL-4/IL-13 for 12 hours and simultaneously with (left) $A_{2 A}$ receptor antagonist Istradefylline or (right) $A_{2 B}$ receptor antagonist PSB0778 and expression of Arg1 was determined by RT-qPCR. (B) The BV-2 microglial cell line was treated with MTA with or without $\mathrm{A}_{2 \mathrm{~B}}$ receptor antagonist PSB0778 for 12 hours and Arg1 expression was measured by RT-qPCR. (C) RAW 264.7 cells were treated with MTA, with or without $A_{2 B}$ receptor antagonist PSB0778 or $A_{2 A}$ receptor antagonist Istradefylline for 12 hours and expression of Timp1, IL10 and Vegfa were determined by RT-qPCR. (D) RAW 264.7 cells were treated with MTA, with or without STAT3 inhibitor Stattic or CREB inhibitor 666-15 for 12 hours, and expression of Timp1, IL10, and Vegfa were determined by RT-qPCR. All statistical comparisons were done using an unpaired student's t-test; $*=P<0.05$, $* *=$ $P<0.005, * * *=P<5 \times 10^{-4}$, n.s. $=$ not significant. 


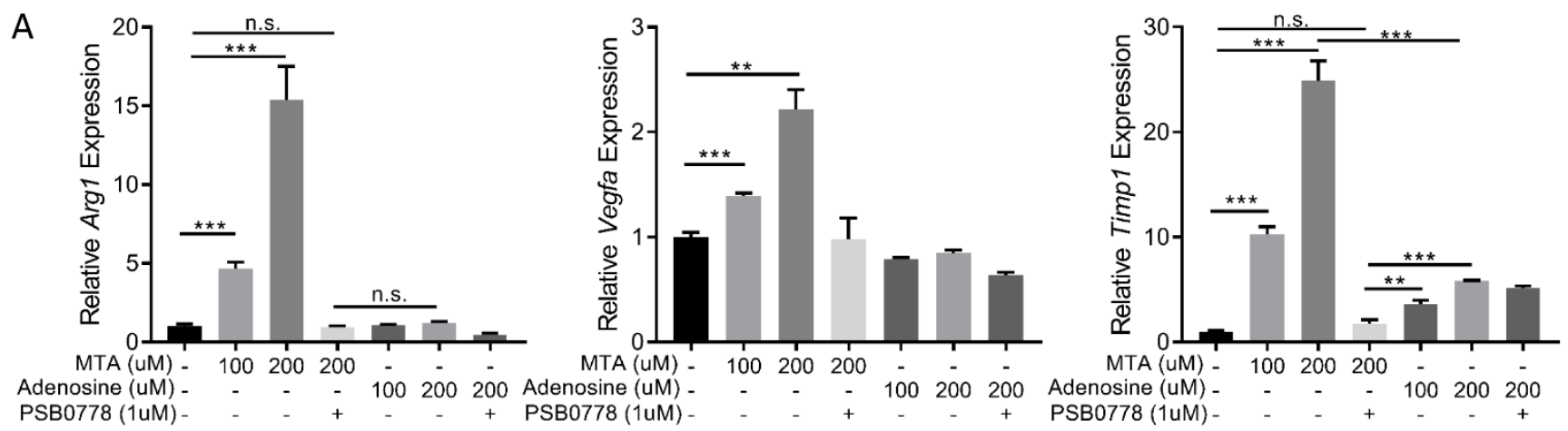

B

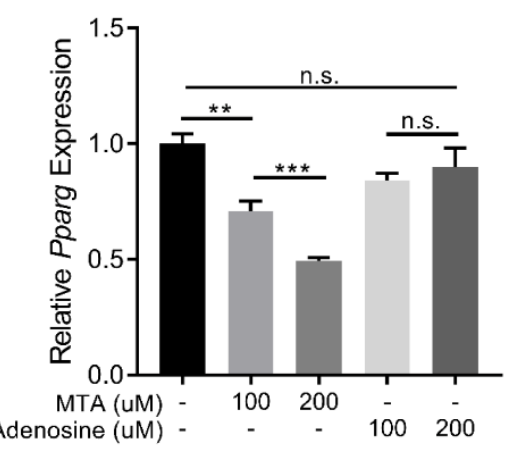

$E$

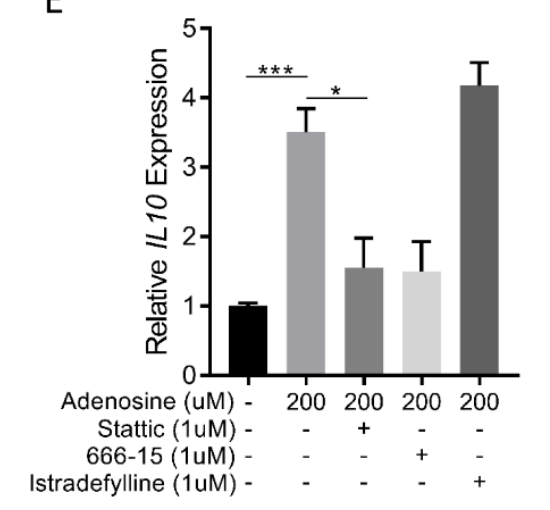

C

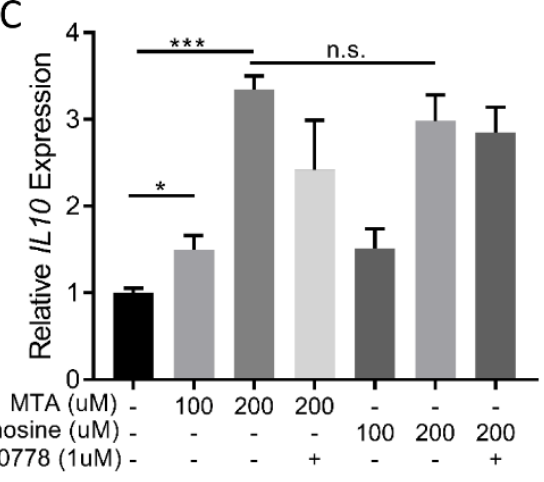

$\mathrm{F}$

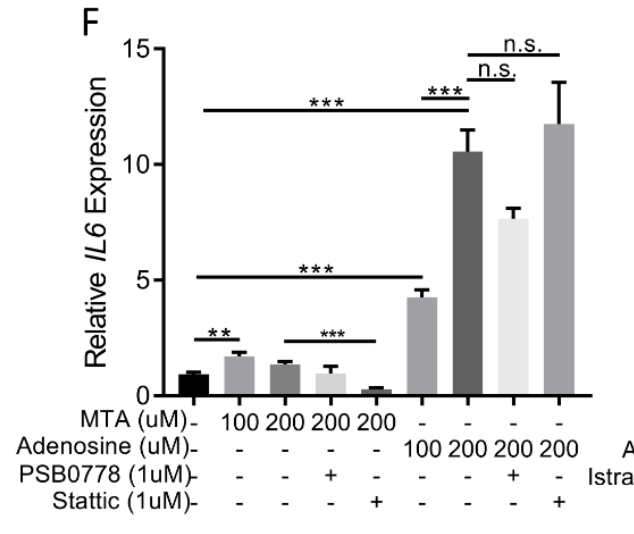

D

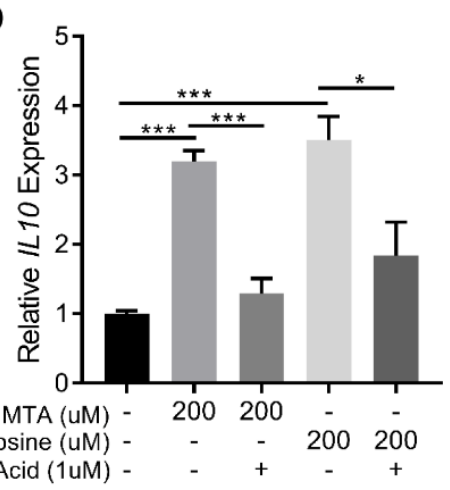

G

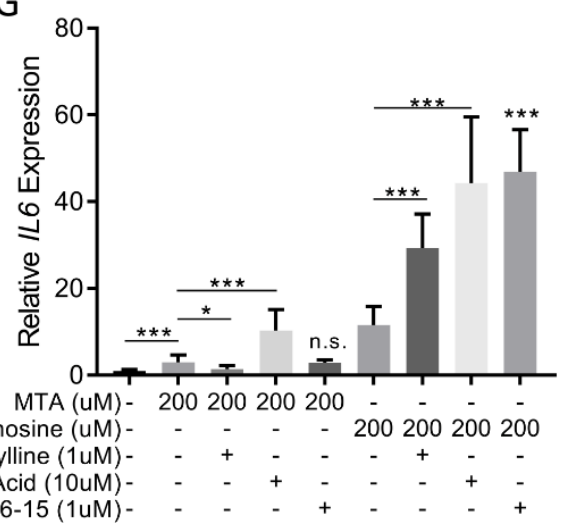

Figure 5. MTA and adenosine have distinct effects. (A) RAW 264.7 cells were treated with the MTA or adenosine with or without $\mathrm{A}_{2 \mathrm{~B}}$ receptor antagonist PSB0778 for 12 hours and Arg1, Vegfa, Timp1 expression were measured by RT-qPCR (B) RAW 264.7 cells were treated with MTA or Adenosine for 12 hours and Pparg expression was measured by RTqPCR. (C and D) Raw 264.7 cells were treated with MTA or adenosine for 12 hours with or without (C) $A_{2 B}$ receptor antagonist PSB0778 or (D) C/EBP inhibitor betulinic acid (B. Acid) as indicated and IL10 expression was measured by RT-qPCR. (E) IL10 expression was measured by RT qPCR following adenosine treatment with or without STAT3 inhibition (Stattic), CREB inhibition (666-15), or $A_{2 A} R$ antagonist Istradefylline. (F and G) RAW 264.7 cells were treated with MTA or adenosine for 12 hours with or without the indicated inhibitors and IL6 expression was measured by RTqPCR. All samples were collected 12 hours after treatment. All statistical comparisons were performed using an unpaired student's t-test; $*=P<0.05, * *=P<0.005, * * *=P<5 \times 10^{-4}$, n.s. $=$ not significant. 


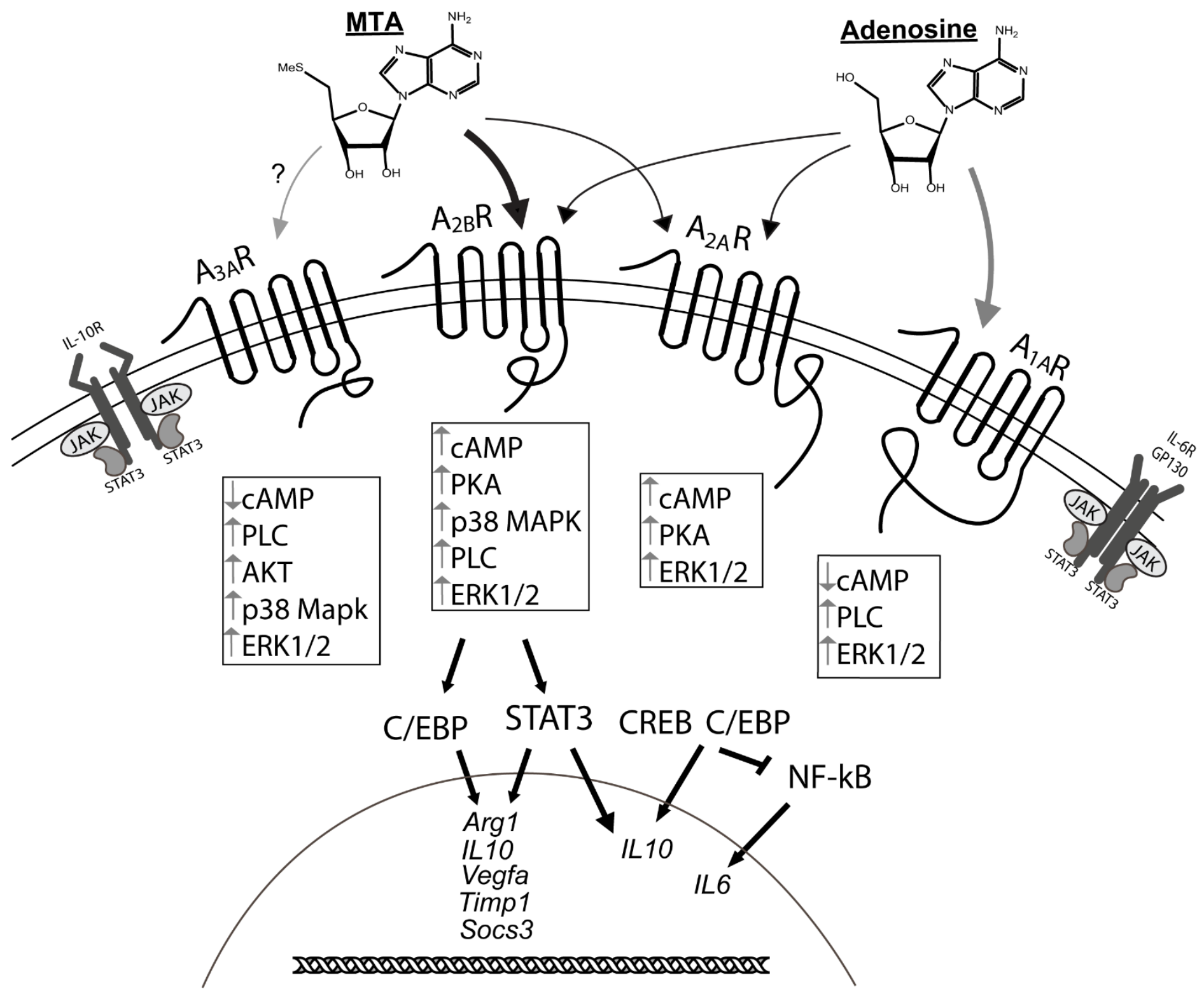

Figure 6. Simplified proposed mechanism of MTA and adenosine-mediated signaling in macrophages. Using small molecule inhibitors specific to the $\mathrm{A}_{2 \mathrm{~B}}$ receptor (PSB0778) and the $\mathrm{A}_{2 \mathrm{~A}}$ receptor (Istradefylline) as well as inhibitors of STAT3 (Stattic), CREB (666-15) and C/EBP (Betulinic Acid), we measured expression of M2 macrophage-associated marker genes following treatment with MTA or adenosine. The ability of MTA to upregulate M2 macrophage marker genes was dependent on $\mathrm{A}_{2 \mathrm{~B}}$ receptor signaling, and required C/EBP and STAT3. Upregulation of IL10 expression by adenosine was blocked by inhibition of STAT3, C/EBP or CREB, while inhibition of the $\mathrm{A}_{2 \mathrm{~A}}$ receptor, C/EBP, or CREB resulted in upregulation of IL6 expression after adenosine treatment. Arrows at the top indicate the receptors that most likely mediate the response to MTA and adenosine, with arrow thickness indicating the degree to which these receptors may be involved. However, both MTA and adenosine will each likely interact with multiple types of adenosine receptors to varying degrees and we did not pharmacologically test the impact of adenosine on the $\mathrm{A}_{1 \mathrm{~A}}$ and $\mathrm{A}_{3 \mathrm{~A}}$ receptors in this model. We saw that $\mathrm{A}_{2 \mathrm{~B}}$ receptor antagonism at the time of MTA treatment fully blocked upregulation of Timp1, Vegfa, and Arg1 but did not completely inhibit IL10 upregulation (Fig. 4b), suggesting MTA signaling is likely being mediated by more than one receptor/pathway, possibly $A_{3 \mathrm{~A}}$, as this receptor has several downstream mediators in common with $\mathrm{A}_{2 \mathrm{~B}}$. Similarly, $\mathrm{A}_{2 \mathrm{~A}}$ receptor antagonism did not block IL10 upregulation in response to adenosine treatment, suggesting involvement of another receptor in activating downstream C/EBP signaling. However, we did see upregulation of IL6 expression following $A_{2 A}$ receptor antagonism at the time of adenosine treatment, indicating that the $A_{2 A}$ receptor does play a role in the signaling balance mediated by adenosine in this model. Furthermore, the different results from CREB and STAT3 inhibition on IL6 expression at the time of Adenosine or MTA treatment strongly indicate different signaling pathways mediating the response to these metabolites. Gray arrows indicate putative pathways based on previous literature (75-77). 